\title{
əThe Budget of Local Available Potential Energy of Low-Frequency Eddies in Northern Hemispheric Winter
}

\author{
XIANGLIN DAI, ${ }^{a}$ YANG ZHANG, ${ }^{a}$ AND XIU-QUn YANG ${ }^{a}$ \\ ${ }^{a}$ China Meteorological Administration-Nanjing University Joint Laboratory for Climate Prediction Studies, Institute for Climate \\ and Global Change Research, School of Atmospheric Sciences, Nanjing University, Nanjing, China
}

(Manuscript received 30 December 2019, in final form 18 October 2020)

\begin{abstract}
Low-frequency (LF) transient eddies (intraseasonal eddies with time scales longer than 10 days) are increasingly found to be important in large-scale atmospheric circulation, high-impact climate events, and subseasonalto-seasonal forecasts. In this study, the features and maintenance of available potential energy of LF eddies (LF EAPE), which denote LF temperature fluctuations, have been investigated. Our study shows that wintertime LF EAPE, with greater amplitude than that of the extensively studied high-frequency (HF) eddies, exhibits distinct horizontal and vertical structures. Different from HF eddies, whose action centers are over midlatitude oceans, the LF EAPE is most active in the continents in the midlatitudes, as well as the subpolar region with shallower vertical structure. By diagnosing the derived energy budget of LF EAPE, we find that, with the strong background temperature gradient in mid- and high-latitude continents (e.g., coast regions along the Greenland, Barents, and Kara Seas), baroclinic generation is the major source of LF EAPE. The generated LF EAPE in the subpolar region is transported downstream and southward to midlatitude continents via background flow. The generated LF EAPE is also dissipated by HF eddies, damped by diabatic effects, and converted to LF EKE via vertical motions. The above energy budget, together with the barotropic dynamics revealed by previous works, suggests multiple energy sources and thus complicated dynamics of LF variabilities.
\end{abstract}

KEYWORDS: Atmospheric circulation; Dynamics; Eddies; Energy transport

\section{Introduction}

With strong connections to daily weather, transient eddy dynamics play a prominent role in extratropical atmospheric dynamics. It has long been appreciated that those traveling eddies, with migratory surface high and low pressure systems and upper-level ridges and troughs, generate the daily variability in winds, temperature, and precipitation in the extratropics. Among those transient eddies, the origin (e.g., Eady 1949; Charney 1947), development (e.g., Simmons and Hoskins 1978; Gutowski et al. 1989; Orlanski and Katzfey 1991), and statistical features (e.g., Trenberth 1991; Chang and Orlanski 1993; Chang et al. 2002; Deng and Mak 2005; Hoskins and Hodges 2002, 2019) of high-frequency eddies (eddies with time scales shorter than 10 days) have been extensively studied as fundamental synoptic topics. Besides their importance to weather phenomena, high-frequency (HF) transient eddies have been realized to play important roles in midlatitude climate. They are the dominant component in extratropical heat and momentum transports (e.g., Oort and Peixoto 1983; Peixoto and Oort 1992; Swanson and Pierrehumbert 1997). They also influence the mean state and the large-scale circulation in midlatitudes by eddy-mean flow interactions (e.g., Stone 1978; Hoskins et al. 1983; Zurita-Gotor and Lindzen 2006; Schneider 2006; Zhang and Stone 2011).

¿ Denotes content that is immediately available upon publication as open access.

Corresponding author: Yang Zhang, yangzhang@nju.edu.cn
Besides HF eddies, the importance of low-frequency (LF) transient eddies (intraseasonal eddies with time scale longer than 10 days) is increasingly revealed. The energy of LF eddies is comparable to and even higher than that of HF eddies (e.g., Blackmon et al. 1984a,b; Lau and Holopainen 1984). The symbiotic relation between low-and high-frequency transient eddies was systematically studied by Cai and Mak (1990) and Cai and van den Dool (1991), in which LF eddies, always with planetary length scale, are found organizing the HF eddies with the latter intensified preferentially downstream of the troughs of the former. Many recent works have shown that LF eddies, by influencing the background temperature distribution, can also anchor the behavior of synoptic eddies and trigger the LF variability of large-scale circulations such as annular modes (Zhang et al. 2012; Nie et al. 2013) and the East Asian trough (Song et al. 2016). The low-frequency eddies are found to play an indispensable and even essential role in extreme events such as floods, persistent heat waves, and cold surges (Jiang et al. 2014; Coumou et al. 2014; Petoukhov et al. 2016; Xie et al. 2019), in which the evolution, propagation, and maintenance of LF eddies are suggested to be critical to the seamless subseasonal-to-seasonal (S2S) forecast.

However, compared to the extensively studied HF eddies, the dynamics of LF eddies are less explored with many key questions remaining to be answered. LF eddies can result from atmospheric response to tropical heating (e.g., Hoskins and Karoly 1981; Sardeshmukh and Hoskins 1988). Tropical convection associated with the MJO is found to be capable of producing wave trains propagating into the middle and high latitudes (e.g., Yoo et al. 2012a,b; Baggett and Lee 2017). Studies (e.g., Simmons et al. 1983; Cai and van den Dool 1991; 
Cai 1992, 2004; Cai et al. 2007) also found that the barotropic effect due to the deformation flow at the exit region of jet stream is a major formation process for the upper-level LF eddies within storm tracks, in which the vorticity flux of HF eddies is found acting to reinforce the LF eddies and retard their propagation. The maintenance of LF eddy kinetic energy (EKE) is further quantified by Jiang and Deng (2011) and Jiang et al. (2013) via diagnosing the local energy budget of LF EKE, in which the interactions between HF and LF eddies are shown to be one of the main sources of LF EKE, especially over the eastern Atlantic and eastern Pacific. Previous studies greatly focused on LF variability observed in the upper troposphere with an equivalent barotropic vertical structure, and emphasized the barotropic generation of LF eddies. Given the above progresses in understanding LF EKE and their barotropic process, the maintenance of LF eddy available potential energy (EAPE), which denotes the temperature fluctuations of longer time scales, is still a missing part in understanding the dynamics of LF eddies.

This study aims to investigate the feature and the maintenance of LF EAPE. By deriving and analyzing the budget equation of LF EAPE, the formation of LF temperature fluctuations, and the interactions between low- and high-frequency eddies as well as the background flow are investigated. Our results show the distinct horizontal and vertical structures of LF EAPE compared with $\mathrm{HF}$ eddies, identify the dominant contribution of baroclinic generation to LF EAPE, and suggest complicated dynamics of LF variabilities. The rest of the paper is organized as follows. Data and methodology used in the study are described in section 2, in which the budget equation of LF EAPE is also derived. Detailed spatial distributions of LF EAPE are shown and compared with LF EKE and HF energies in section 3. The budget of LF EAPE is analyzed in section 4, in which the formation, transportation, and conversion of LF EAPE from/to other forms of energies are discussed. The possible origin of baroclinic generation and the relation between LF EAPE and EKE are discussed in section 5. The key findings are summarized in section 6 .

\section{Data and methodology}

\section{a. Data}

This study applies the daily temperature $T$, velocity $u, v, \omega$, and geopotential height $Z$ of the ERA-Interim dataset from the European Centre for Medium-Range Weather Forecasts
(Dee et al. 2011) from the years 1979 to 2016 with $1.5^{\circ} \times 1.5^{\circ}$ spatial resolution at 12 pressure levels (from the surface to $100 \mathrm{hPa}$ ). The reanalysis data from the National Centers for Environmental Prediction (NCEP)-National Center for Atmospheric Research (NCAR) over the same time with $2.5^{\circ}$ spatial resolution are also checked to confirm the results (which are similar thus not shown).

Variables $T, u, v, \omega$, and $Z$ are divided into the winter [December-February (DJF)] mean $T_{m}, u_{m}, v_{m}, \omega_{m}$, and $Z_{m}$ and transient eddy $T^{\prime}, u^{\prime}, v^{\prime}, \omega^{\prime}$, and $Z^{\prime}$ components, respectively. A prime (') denotes a transient eddy component and a subscript $m$ denotes seasonal mean. The transient eddy, after removing its seasonal cycle, is further divided into high-frequency $T_{h}^{\prime}, u_{h}^{\prime}, v_{h}^{\prime}, \omega_{h}^{\prime}, Z_{h}^{\prime}$ and low-frequency $T_{l}^{\prime}, u_{l}^{\prime}, v_{l}^{\prime}, \omega_{l}^{\prime}, Z_{l}^{\prime}$ parts, using the Lanczos 10-day high- and low-pass filter, respectively. The seasonal cycle is defined as the first four Fourier harmonics of the 37 years' daily climatology.

\section{b. Energy budget analysis}

The definitions of EKE (denoted by $K$ ) and EAPE (denoted by $A$ ) are the same as in Orlanski and Katzfey (1991), which are modified from those proposed by Lorenz (1955). The EKE is defined as

$$
K=\frac{1}{2}\left(u^{\prime 2}+v^{\prime 2}\right),
$$

and EAPE is defined as

$$
A=-\frac{\alpha_{m}}{2 \theta_{m}} \frac{\theta^{2}}{\Gamma}
$$

where $\theta^{\prime}$ is the transient component of potential temperature and $\alpha_{m}$ is the seasonal mean of the inverse of density. The stratification parameter $\Gamma=d \tilde{\theta} / d p$, with $\tilde{\theta}$ denoting the hemispheric and time averaged potential temperature. The EKE and EAPE of low-frequency eddies thus are

$$
K_{l}=\frac{1}{2}\left(u_{l}^{\prime 2}+v_{l}^{\prime 2}\right), A_{l}=-\frac{\alpha_{m}}{2 \theta_{m}} \frac{\theta_{l}^{\prime 2}}{\Gamma} .
$$

To quantify the formation and maintenance of LF EAPE, its budget equation is derived from the thermodynamic equation, similar to Lorenz (1955) and Orlanski and Katzfey (1991):

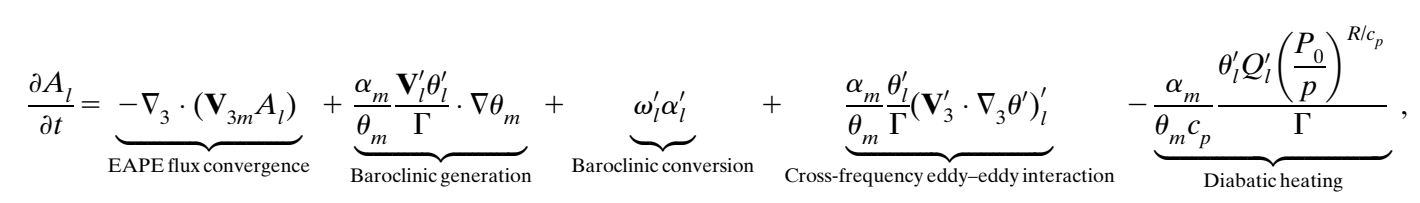

where $\mathbf{V}_{3}$ denotes the three-dimensional wind vector. The detailed derivation of LF EAPE budget is provided in appendix A.

The first term on the right-hand side (rhs) of Eq. (4) denotes the energy flux convergence (EFC) due to the advection by DJF mean flow. The advection cannot generate or dissipate energy. Its contribution is to transport energy downstream by the mean flow. The second term on the rhs of Eq. (4), which is the product of mean temperature gradient and eddy heat flux, represents the 
TABLE 1. Abbreviations and definitions of the LF EAPE budget.

\begin{tabular}{|c|c|c|c|c|c|c|}
\hline Abbreviations & LF EAPE & EFC & BG & $\mathrm{BC}$ & CFEI & $S$ \\
\hline Formula & $-\frac{\alpha_{m}}{2 \theta_{m}} \frac{\theta_{l}^{2}}{\Gamma}$ & $-\nabla_{3} \cdot\left(\mathbf{V}_{3 m} A_{l}\right)$ & $\frac{\alpha_{m}}{\theta_{m}} \frac{\mathbf{V}_{l}^{\prime} \theta_{l}^{\prime}}{\Gamma} \cdot \nabla \theta_{m}$ & $\omega_{l}^{\prime} \alpha_{l}^{\prime}$ & $\frac{\alpha_{m}}{\theta_{m}} \frac{\theta_{l}^{\prime}}{\Gamma}\left(\mathbf{V}_{3}^{\prime} \cdot \nabla_{3} \theta^{\prime}\right)_{l}$ & $\alpha_{m} \theta_{l}^{\prime} Q_{l}^{\prime}\left(\frac{P_{0}}{p}\right)^{R / c_{p}}$ \\
\hline Definition & LF EAPE & $\begin{array}{l}\text { Energy flux } \\
\text { convergence }\end{array}$ & $\begin{array}{l}\text { Baroclinic } \\
\text { generation }\end{array}$ & $\begin{array}{l}\text { Baroclinic } \\
\text { conversion }\end{array}$ & $\begin{array}{c}\text { Cross-frequency } \\
\text { eddy-eddy } \\
\text { interaction }\end{array}$ & $\begin{array}{c}\overline{\theta_{m} c_{p}} \\
\text { Diabatic heating }\end{array}$ \\
\hline
\end{tabular}

baroclinic generation, which transfers energy from mean available potential energy (APE) to LF EAPE. The third term on the rhs of Eq. (4) denotes the energy conversion between LF EAPE and LF EKE and is often referred to as baroclinic conversion term (BC), through which energy is converted from EAPE to EKE by the upward motion of warm air and downward motion of cold air. The fourth term on the rhs of Eq. (4) denotes energy transfer via cross-frequency eddy-eddy interaction (CFEI). Note that the CFEI term can be further divided into terms denoting eddies with different frequencies interacting with LF eddies. As shown in Eq. (5), this term can be decomposed into nonlinear self-interaction among LF eddies [first term on the rhs of Eq. (5)], interaction among HF eddies that contributes to lowfrequency variability and energy [second term on the rhs of Eq. (5)], and direct interaction between LF and HF eddies [third term on the rhs of Eq. (5)], respectively:

$$
\underbrace{\frac{\alpha_{m}}{\theta_{m}} \frac{\theta_{l}^{\prime}}{\Gamma}\left(\mathbf{V}_{3}^{\prime} \cdot \nabla_{3} \theta^{\prime}\right)_{l}^{\prime}}_{\text {Cross-frequency eddy-eddy interaction }}=\underbrace{\frac{\alpha_{m}}{\theta_{m}} \frac{\theta_{l}^{\prime}}{\Gamma}\left(\mathbf{V}_{3 l}^{\prime} \cdot \nabla_{3} \theta_{l}^{\prime}\right)_{l}^{\prime}}_{\text {LF-LF eddy interaction }}+\underbrace{\frac{\alpha_{m}}{\theta_{m}} \frac{\theta_{l}^{\prime}}{\Gamma}\left(\mathbf{V}_{3 h}^{\prime} \cdot \nabla_{3} \theta_{h}^{\prime}\right)_{l}^{\prime}}_{\text {HF-HF eddy interaction }}+\underbrace{\frac{\alpha_{m}}{\theta_{m}} \frac{\theta_{l}^{\prime}}{\Gamma}\left(\mathbf{V}_{3 l}^{\prime} \cdot \nabla_{3} \theta_{h}^{\prime}+\mathbf{V}_{3 h}^{\prime} \cdot \nabla_{3} \theta_{l}^{\prime}\right)_{l}^{\prime}}_{\text {direct HF-LF eddy interaction }} .
$$

The last term on the rhs of Eq. (4) denotes the contribution of diabatic heating to LF EAPE. The diabatic heating $Q$ in the study is diagnosed as a residual from the thermodynamic equation, and then the LF diabatic heating $Q_{l}$ is obtained via the LF filter after its seasonal cycle and seasonal mean are removed. Table 1 shows the full list of the abbreviations and definitions of each term in the LF EAPE budget. Equation (4) is consistent with the budget equation derived in the work of Lu (2017). By diagnosing the derived budget equation, local balance of LF EAPE can be quantified, which helps to further understand the maintenance of LF eddies.

\section{Spatial distribution of low-frequency eddy available potential energy}

Spatial distributions of wintertime LF EAPE are displayed in Figs. 1-3, in which distributions of HF eddy energies are also plotted for comparison. Compared to the zonal mean $\mathrm{HF}$ EAPE in Fig. 1a, which peaks around $45^{\circ} \mathrm{N}$ at $500 \mathrm{hPa}$, the zonal mean LF EAPE (Fig. 1b) peaks both around $500 \mathrm{hPa}$ and near the surface, with stronger amplitude. The intensity of LF EAPE is as strong as the LF EKE (Fig. 1d). This feature is different from HF eddies, for which the intensity of EAPE is much weaker than that of EKE (Fig. 1e). Furthermore, the action centers of LF eddies are located at higher latitudes compared to HF eddies, peaking slightly north of $60^{\circ} \mathrm{N}$, similar to that in the Southern Hemisphere as in Nie et al. (2013).

Since previous studies on the barotropic process of LF variability suggest different dynamics for fluctuations with 10-30- day and >30-day time scales (e.g., Blackmon et al. 1984a,b), we decompose the LF EAPE into contributions from eddies with time scales of 10-30 and 30-90 days as well to investigate whether differences also exist in baroclinic process. As shown in Figs. 1c and 1d, eddies with the two time scales exhibit similar vertical and latitudinal distributions of LF EAPE in the troposphere, peaking around the subpolar upper-level and surface regions. However, the LF EAPE for eddies with longer time scales shows a unique stratospheric action center near the polar region, suggesting its close connection with the variability of polar vortex. For spatial distributions of EKE, however, differences between those for eddies with 10-30- and 3090-day time scales are small. They all peak in subtropics and midlatitudes, with the 10-30-day EKE slightly stronger.

The detailed horizontal distributions of eddy energies are displayed in Fig. 2, in which energies averaged vertically through the troposphere (between 300 and $1000 \mathrm{hPa}$ ) are plotted. Different from HF eddies (Figs. 2a,b), whose EAPE and EKE are most active over oceans in the subtropics and midlatitudes, the LF EAPE (Fig. 2c) is strongest over continents in higher latitudes. In the Eurasian continent, the LF EAPE peaks around the $60^{\circ} \mathrm{N}$ latitudinal belt from the coast of the Barents-Kara Seas to East Asia. The strong LF EAPE also extends to the Bering Strait, Alaska, along the coast, and reaches another stronger peak from the northern continental area of North America to Greenland. Note that, with the map projection used in the figure, the area of high latitude is amplified. The LF EKE, however, is most active over the east of the North Pacific and North Atlantic. The distinct spatial 


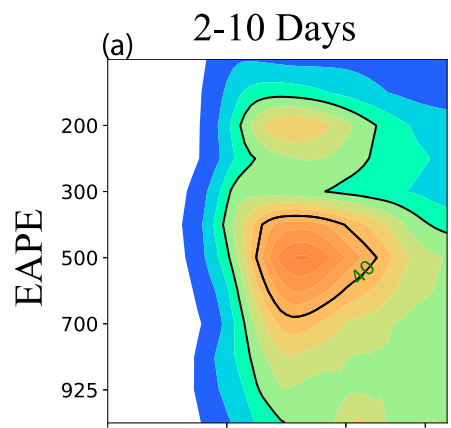

(e)

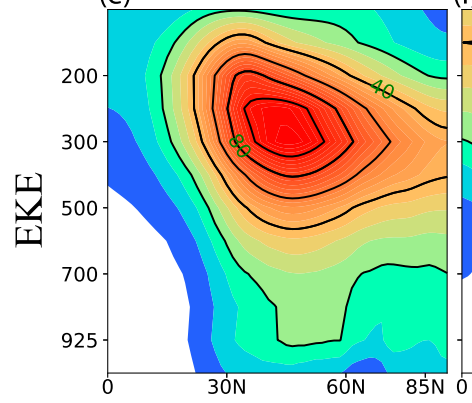

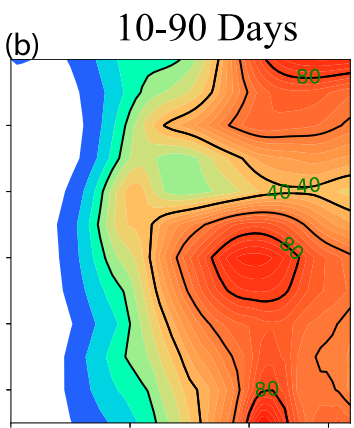

(f)

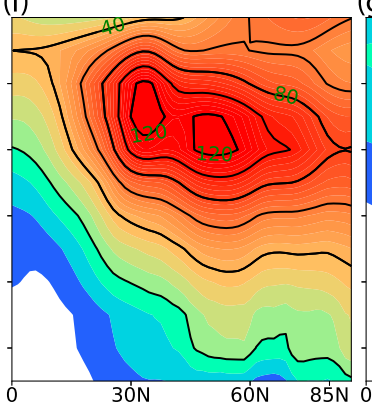

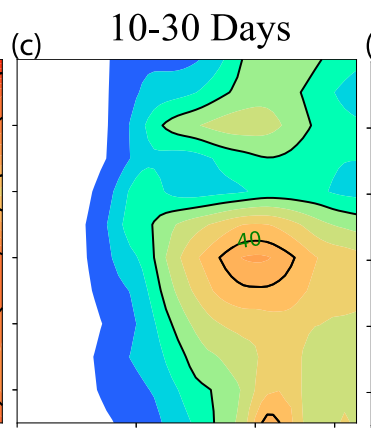

(g)

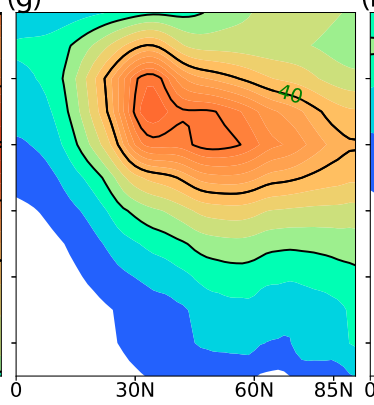

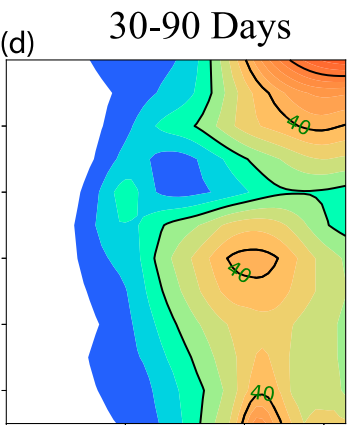

(h)

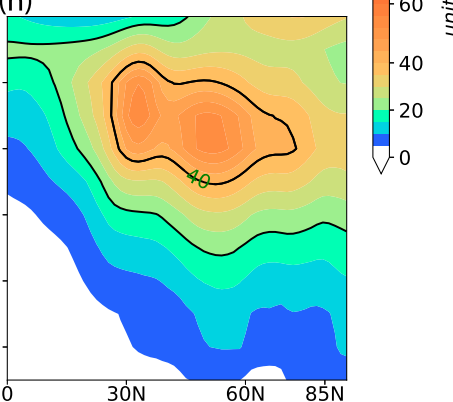

FIG. 1. Cross section of zonal mean EAPE of (a) high-frequency eddies (time scale of 2-10 days) and (b) low-frequency eddies (time scale of 10-90 days). The latter is further decomposed into the parts for eddies with time scales of (c) 10-30 and (d) 30-90 days. (e)-(h) As in (a)-(d), respectively, but for EKE.

distributions between LF EAPE and LF EKE may imply a shallower vertical structure of EAPE, which cannot reach higher levels and convert to EKE as HF eddies. Horizontal distributions of LF eddy energies contributed by eddies with time scales of 10-30 days and longer than 30 days are also plotted in Figs. 2e-h. In Eurasia, the eddies with time scales of 10-30 and 30-90 days make comparable contributions to the total LF EAPE. In North America, the eddies with time scale longer than 30 days are stronger and contribute more to the LF EAPE. For LF EKE, eddies from both time scales are active with comparable intensity.

As the LF EAPE is strongest over the continents in midlatitude and subpolar regions, the vertical and zonal structures of LF eddies in both middle (over $20^{\circ}-60^{\circ} \mathrm{N}$ ) and high (over $60^{\circ}-70^{\circ} \mathrm{N}$ ) latitudes are displayed in Fig. 3, respectively. In midlatitudes, compared to HF EAPE in Fig. 3a, which peaks around $500 \mathrm{hPa}$ in the North Pacific $\left(180^{\circ} \mathrm{E}\right)$ and North Atlantic $\left(60^{\circ} \mathrm{W}\right)$, the LF EAPE (Fig. 3b) shows a strong peak near the surface over the Eurasian $\left(60^{\circ}-120^{\circ} \mathrm{E}\right)$ and North American $\left(120^{\circ}-60^{\circ} \mathrm{W}\right)$ continents. In the subpolar region, as shown in Figs. $3 e$ and $3 f$, the different vertical structures of EAPE between LF and HF eddies are more evident. In Eurasia, the LF EAPE is strong and greatly confined near the surface. From the Bering Strait to North America, the LF EAPE exhibits strong activity both near the surface and in the upper troposphere. The LF EAPE is active over the whole troposphere in North America, with connections to the temperature variability in the stratosphere as well. The deeper vertical structure of LF EAPE in North America helps explain its stronger amplitude in vertical average than that in Eurasia in Fig. 2c.
The vertical-zonal distributions of LF EAPE contributed from eddies with time scales of 10-30 and 30-90 days in middle and high latitudes are also displayed in Figs. 3c, 3d, 3g, and 3h, respectively. In the midlatitudes, the LF EAPE are strong and show similar distributions at both time scales. In higher latitudes, the surface action centers in Eurasia and Bering Strait are also strong at both time scales. In North America, the LF EAPE is stronger at time scales of 30-90 days, for which the stratospheric subseasonal variability is implied to play a role, consistent with the result in Fig. 2, while the LF EKE is stronger on the 10-30-day time scale. The above spatial distributions of EAPE are distinct from that of EKE, which, as shown in Figs. 2i-1, peaks near the tropopause in the North Pacific and North Atlantic basins.

From the above analysis, the distributions of eddy energies are summarized as follows:

- The intensity of boreal winter LF EAPE is much stronger than the HF EAPE with an additional strong peak near the surface.

- Different from HF eddies, which are most active over ocean basins, the LF EAPE is mostly centered on the continents in the middle and high latitudes. It is active over almost the whole subpolar latitude belt with peaks in the Eurasia continent extending from the coast of the Barents-Kara Seas to East Asia and the Bering Strait and in the continent of North America to Greenland.

- The vertical structure of LF EAPE shows double peaks ( $500 \mathrm{hPa}$ and near surface) in the North American region. However, in Eurasia, the action center of LF EAPE is mostly confined near the surface of the continent. 
(a)

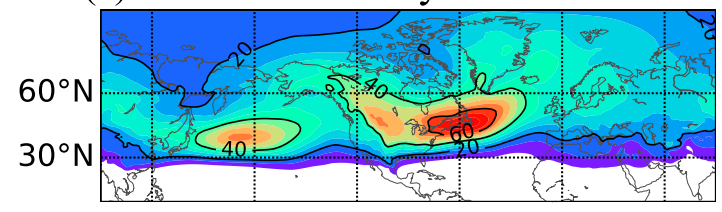

(c)

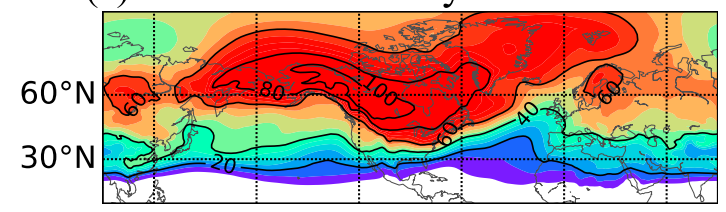

(e)

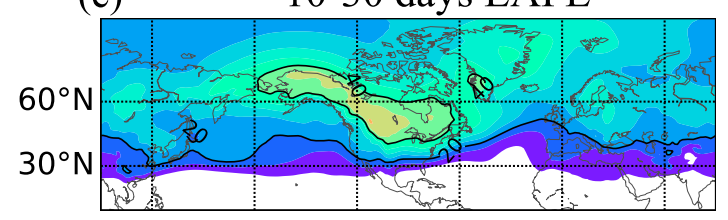

(g) 30-90 days EAPE

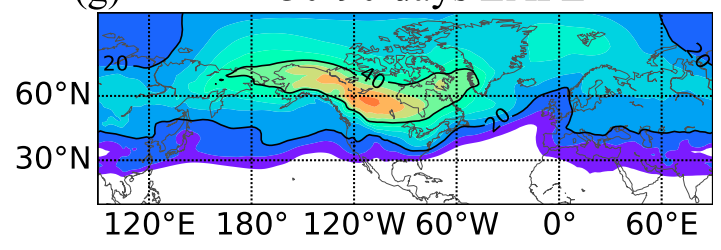

(b)

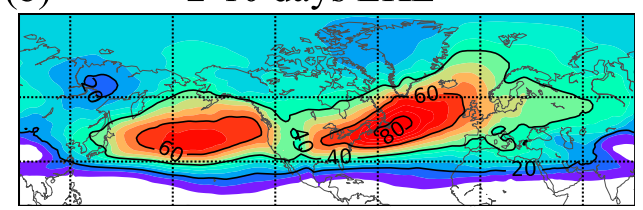

(d)

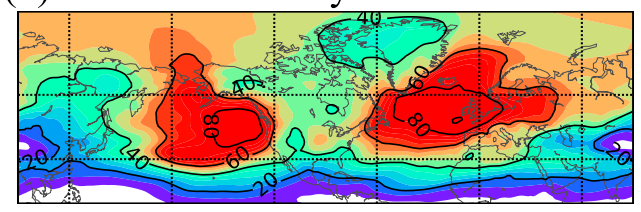

(f)

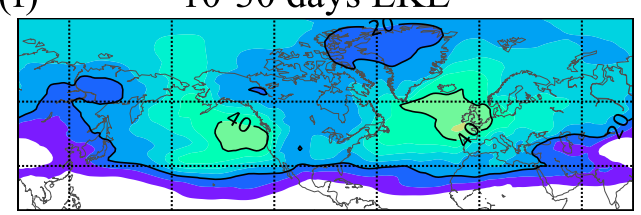

(h)

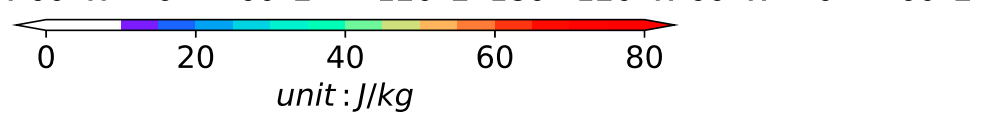

FIG. 2. Horizontal distribution of wintertime transient eddy available potential energy (EAPE) and eddy kinetic energy (EKE), respectively, averaged between 300 and $1000 \mathrm{hPa}$ in Northern Hemisphere for eddies with time scales of (a),(b) 2-10, (c),(d) 10-90, (e),(f) 10-30, and (g),(h) 30-90 days. Contour interval is $20 \mathrm{~J} \mathrm{~kg}^{-1}$ for all panels.

- The EAPE in Eurasia and North America is active at time scales of both 10-30 and 30-90 days. In North America, the LF EAPE at the longer time scale (30-90 days) is even stronger and shows connections with the stratospheric variability.

The above different features between high- and low-frequency eddies imply the different dynamical processes that maintain the high- and the low-frequency EAPE. In the next section, we further analyze the formation, conversion, and transportation process by using the EAPE budget.

\section{Budget analysis of low-frequency EAPE}

\section{a. Vertical structure of the LF EAPE budget}

In this section, the formation and maintenance of LF EAPE is investigated by analyzing its energy budget as quantified in Eq. (4). Vertical-latitudinal distributions of each zonal averaged budget terms are shown in Fig. 4. The budget analysis shows that the major source of LF EAPE is the baroclinic generation (Fig. 4a). The generated LF EAPE is partly converted to LF EKE by baroclinic conversion term (Fig. 4b) and partly transferred to HF EAPE through the cross-frequency eddy-eddy interactions (Fig. 4c). The remaining LF EAPE is damped by the diabatic heating effect (Fig. 4d). Note that, given the small mean meridional wind, the zonal average of the flux convergence term is much smaller than the above terms and thus is not displayed. The baroclinic generation term, as in Fig. 4a, acts as the source term over the whole troposphere and peaks slightly north of $60^{\circ} \mathrm{N}$. The spatial distributions of the baroclinic generation term well match the distributions of LF EAPE, especially in the lower troposphere over high latitudes, indicating its dominant role as the major source of LF EAPE. The baroclinic conversion term in Fig. 4b is negative throughout the troposphere, with a peak at $500 \mathrm{hPa}$ around the north of $60^{\circ} \mathrm{N}$ and a second peak in $30^{\circ} \mathrm{N}$. It indicates that part of the generated LF EAPE is converted to LF EKE via the LF vertical motion in the region. The cross-frequency eddy-eddy interaction term in Fig. $4 \mathrm{c}$ is also negative and most active around $500 \mathrm{hPa}$ from the middle to high latitudes, suggesting that the generated LF EAPE is also transferred to HF EAPE via the nonlinear eddy-eddy interactions. Around the north of $60^{\circ} \mathrm{N}$, the eddy-eddy interaction is active throughout the whole troposphere. The CFEI term is further decomposed as in Eq. (5). Distributions of each component are also displayed in Fig. 5. The dominant contribution in CFEI term is the interaction between HF eddies, which dissipates the LF EAPE in 


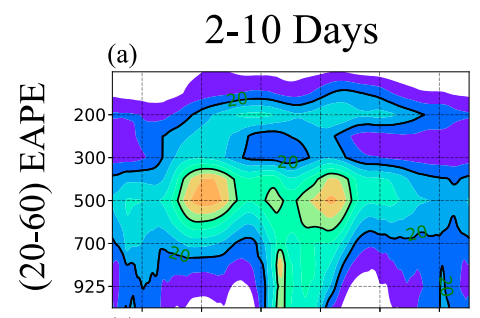

(e)

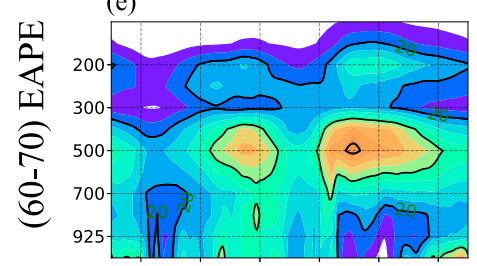

(i)

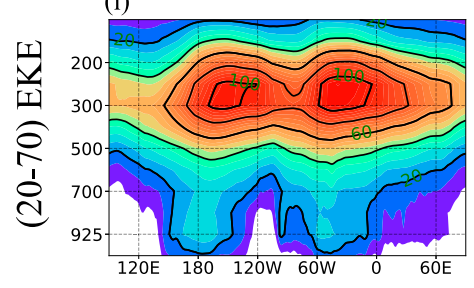

10-90 Days

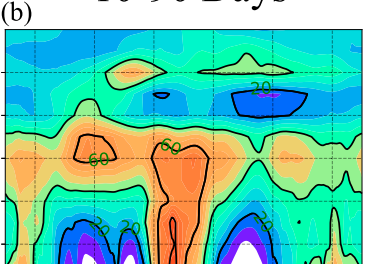

(f)

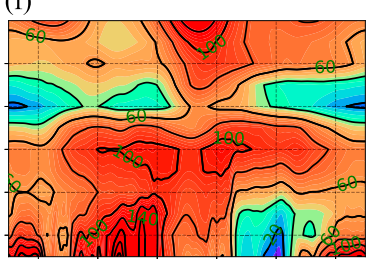

(j)

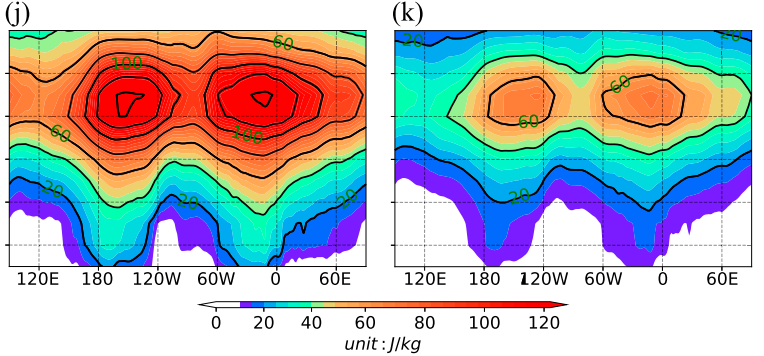

10-30 Days

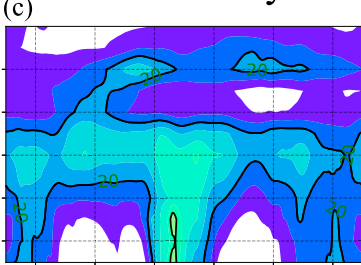

(g)

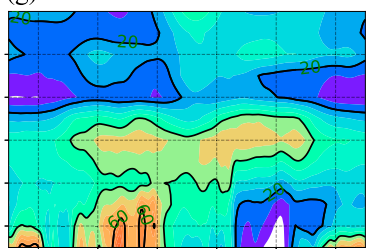

(k)

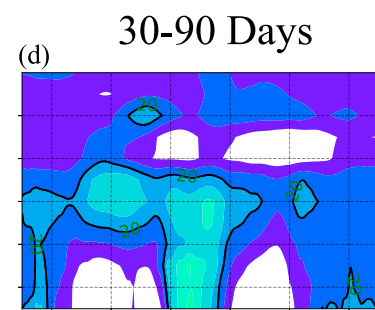

(h)

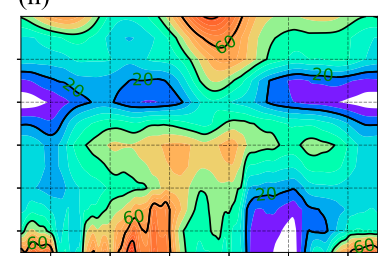

(1)

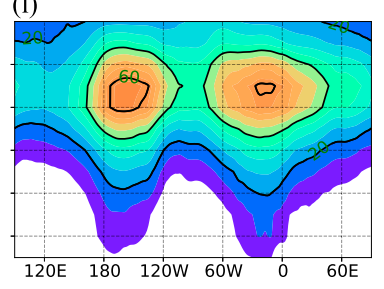

FIG. 3. Vertical-longitude distributions of wintertime transient eddy available potential energy (EAPE) in midlatitudes (averaged between $20^{\circ}$ and $60^{\circ} \mathrm{N}$ ) for eddies with time scales of (a) 2-10, (b) 10-90, (c) 10-30, and (d) 30-90 days. (e)-(h) As in (a)-(d), but for EAPE averaged over higher latitudes $\left(60^{\circ}-70^{\circ} \mathrm{N}\right)$. (i)-(1) As in (a)-(d), but for eddy kinetic energy (EKE) averaged over $20^{\circ}-70^{\circ} \mathrm{N}$. Contour interval is $20 \mathrm{~J} \mathrm{~kg}^{-1}$ for all panels.

the troposphere and acts to generate the LF variability in the stratosphere. The self-interaction between LF eddies and the direct HF-LF eddy interaction plays secondary roles in the LF EAPE budget. The diabatic heating term in Fig. $4 \mathrm{~d}$ is negative and mostly concentrated in lower troposphere, implying that the vertical thermal mixing triggered by surface heat flux mostly acts to damp the low-frequency temperature fluctuations, and thus LF EAPE.

Vertical-longitude distributions of each term in the LF EAPE budget equation are also displayed in Fig. 6. Given the latitudinal distributions of LF EAPE, the energy budget term is also averaged over the middle $\left(20^{\circ}-60^{\circ} \mathrm{N}\right)$ and high latitudes $\left(60^{\circ}-70^{\circ} \mathrm{N}\right)$. In the midlatitudes, the baroclinic generation is most active over the North Pacific and the North American/ North Atlantic regions (Fig. 6a). A much stronger baroclinic generation term is observed in high latitudes, peaking near the surface over Eurasia and the Bering Strait/east coast of the North America/Greenland region (Fig. 6b). In midlatitudes, the generated LF EAPE over the North Pacific and North American/North Atlantic regions is greatly converted to LF EKE via the baroclinic conversion term as shown in Fig. 6c, whose spatial distributions are in general similar to that of baroclinic generation term in the free troposphere (Fig. 6a) but with the opposite sign. The eddy-eddy cross-frequency interactions (Fig. 6e) and diabatic damping (Fig. 6g) also act to partly balance the baroclinic generation locally in the upper troposphere and near the surface, respectively. In high latitudes, the generated LF EAPE near the surface over Eurasia and the Bering Strait, east coast of North America, and Greenland is greatly balanced by the eddy-eddy cross-frequency interactions and diabatic damping. The spatial distributions of crossfrequency interactions in troposphere in Fig. 6f are roughly similar to that of baroclinic generation term but with the opposite sign, suggesting that a great part of LF EAPE is transferred to HF EAPE locally by the nonlinear eddy-eddy interaction. Part of the surface generated LF EAPE is also locally damped by diabatic heating (Fig. 6h). The baroclinic conversion term in the high latitudes is most active and acts to convert the LF EAPE to EKE in the upper troposphere and the stratosphere over the Bering Strait and the east coast of North America to the Barents-Kara Seas. The EAPE flux term acts to extend the generated LF EAPE eastward, especially in the upper troposphere where the westerly jet is strong in both the middle and high latitudes (Figs. 6i,j).

\section{b. Horizontal distributions of the LF EAPE budget}

Horizontal distributions of each energy budget term in LF EAPE are also displayed in Fig. 7 to better understand the local energy balance. Given that the LF EAPE is most active near the surface and in the upper troposphere, each energy budget term is vertically averaged between 700-1000 and 300$500 \mathrm{hPa}$ correspondingly. Near the surface, the baroclinic generation term is the dominant source term for LF EAPE, with action centers along the coast of the continents in the 
(a) Baroc. Gen
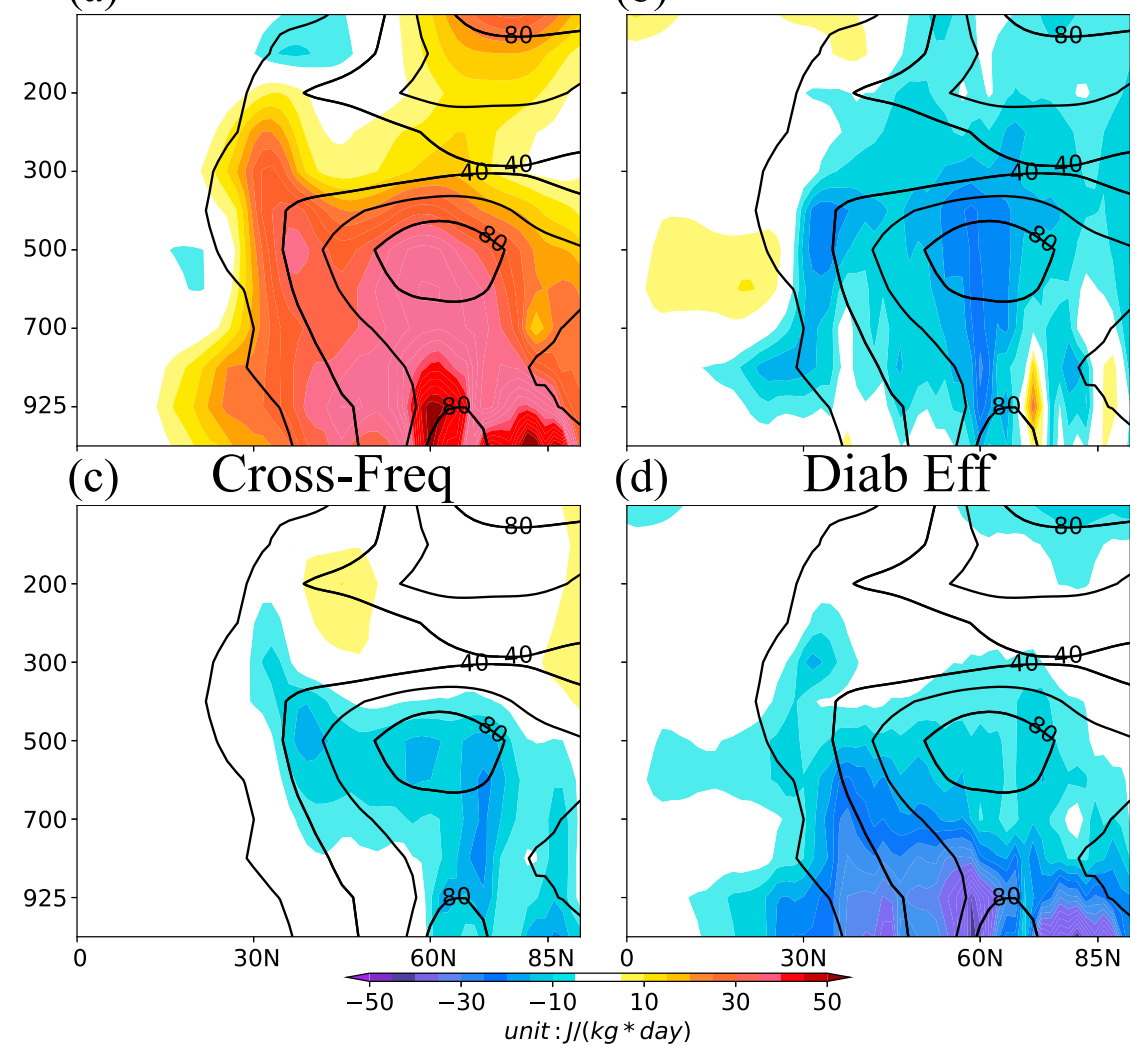

FIG. 4. Vertical-latitudinal distributions of the zonal average of each budget term for LF EAPE: (a) baroclinic generation term, (b) baroclinic conversion term, (c) cross-frequency eddy-eddy interaction term, and (d) diabatic term (computed as residual). Spatial distributions of zonal mean EAPE are also plotted in contours for comparison. In all panels, EAPE greater than $20 \mathrm{~J} \mathrm{~kg}^{-1}$ is plotted with contour interval of $20 \mathrm{~J} \mathrm{~kg}^{-1}$. (b) Baroc. Con

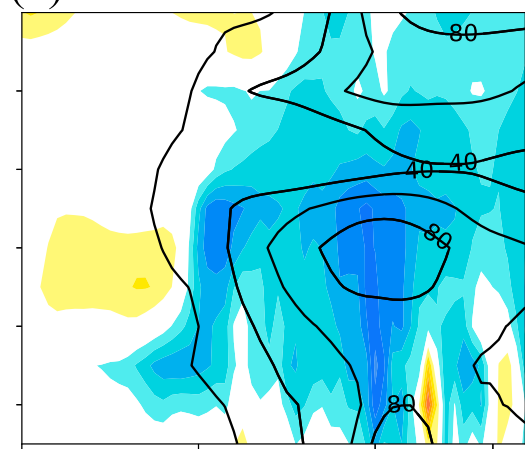

(d) Diab Eff middle and high latitudes. As shown in Fig. 7a, the strongest action centers are observed from the coast of the GreenlandBarents-Kara Seas to East Asia, the Bering Strait, and Alaska across to Hudson and Baffin Bays in the east coast of North America. These coastal regions are also the areas characterized by strong temperature gradients in the winter season. Consistent with the results in Fig. 6 for high latitudes, the crossfrequency eddy-eddy interaction term (Fig. 7c) shows a similar spatial pattern to Fig. 7a but with the opposite sign, suggesting that the generated LF EAPE is greatly balanced by crossfrequency term with energy transferred to HF EAPE. The generated LF EAPE is also partly converted to LF EKE from East Asia to the Bering Strait and from the east coast of North America to the Greenland Sea (Fig. 7b), and damped locally by diabatic effect (Fig. 7d). The diabatic effect near the surface is strongest along the coastal regions, where the temperature contrasts are strong. In those regions, it is likely that the warm air above ocean surface is advected to cold land or cold air above land surface is advected to warm ocean, resulting in strong surface heat flux to damp the temperature fluctuation. The energy flux term in Fig. 7e shows zonal dipolar structures 


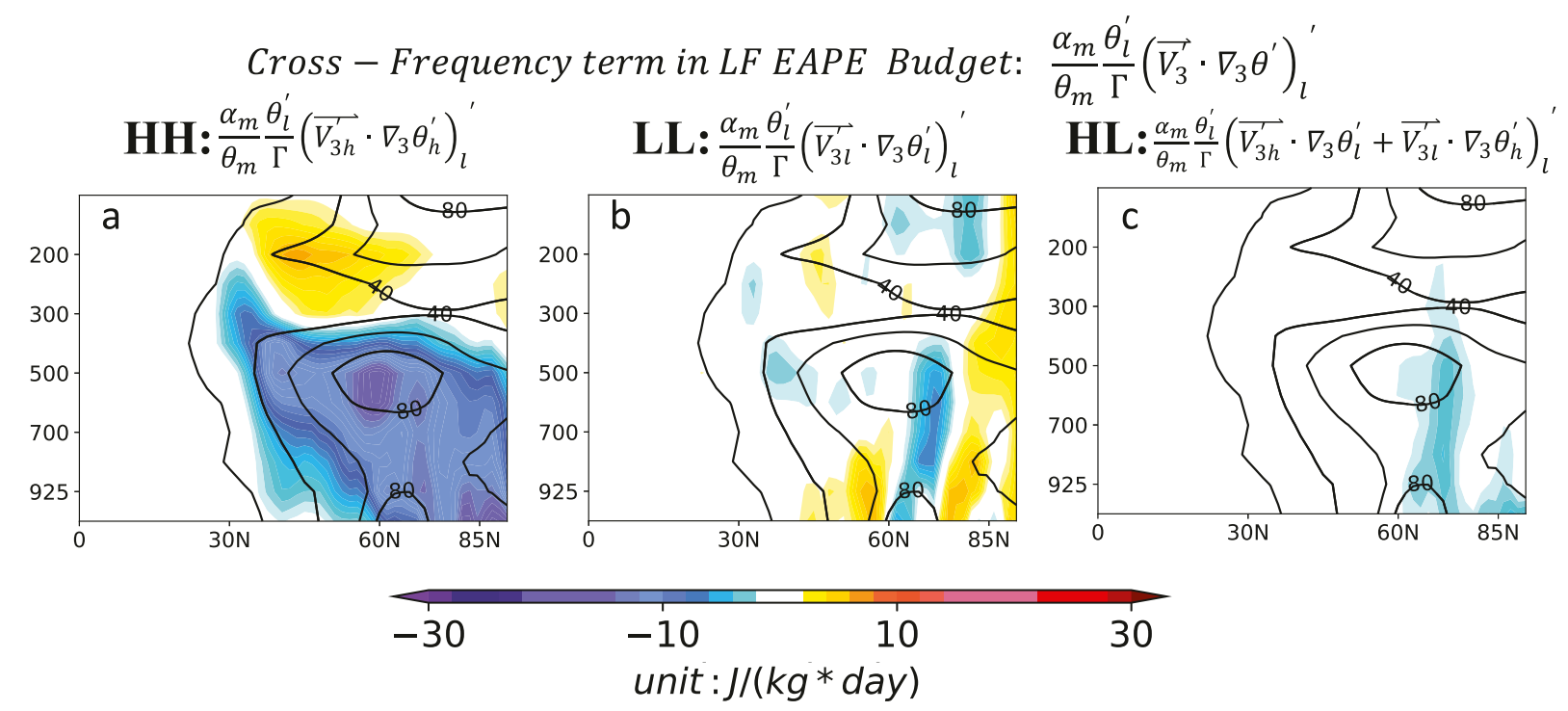

FIG. 5. Vertical-latitudinal distributions of zonal averaged each component in CFEI term: (a) interaction between high-frequency eddies, (b) self-interaction between low-frequency eddies, and (c) direct interaction between high- and low-frequency eddies.

In this section, by investigating the LF EAPE budget, the main results are summarized as follows:

1) Baroclinic generation is the dominant source term for LF EAPE, which draws energy from the mean state to LF EAPE. The cross-frequency eddy-eddy interaction and baroclinic conversion terms act to transfer LF EAPE to HF EAPE and LF EKE, respectively. The generated LF EAPE is also damped locally by the diabatic effect in the lower troposphere.

2) Horizontal distributions of LF EAPE budget show that the generation, conversion, and damping processes are active mostly over the continents in the middle and high latitudes in the lower troposphere, from the coast of the GreenlandBarents-Kara Seas to East Asia, the Bering Strait, and the east coast of North America, and active in the upper troposphere along the jet streams, extending from the east coasts of continents to the west of North Pacific and North Atlantic.

3) The LF EAPE exhibits different features of energy balance in the lower and upper troposphere. Near the surface, the generated LF EAPE is transferred to HF EAPE, damped locally by diabatic effect, and converted to LF EKE over North Pacific and North Atlantic. In the upper troposphere, the generated LF EAPE is advected to downward regions along the jet streams and converted to LF EKE.

Since the distributions of EAPE for eddies with time scales of 10-30 and 30-90 days are also investigated in the last section, their energy budgets are analyzed as well, whose results are included in appendix B. The energy budget for the two time scales shows a similar balance near the surface. In the upper troposphere, the energy balance for the two time scales is roughly similar, with the CFEI term exhibiting more differences. The CFEI term acts as a source of the 10-30-day variability in the polar regions in East Siberia and the Chukchi Sea instead of acting to dissipate LF EAPE on a 3090-day time scale.

\section{Discussion}

\section{a. On the baroclinic generation}

In the last section, we have investigated the energy budget and found that baroclinic generation is the major source of LF EAPE. Here we further investigate the two major components in baroclinic generation term, the background baroclinicity and the heat flux of LF eddies. As shown in Fig. 8a, the wintertime background temperature gradient always peaks along the coastal regions in the middle and high latitudes, especially along the Bering Strait and the Greenland-Barents-Kara Seas, and in the subtropics in the East Asia/northwest Pacific and northwest Atlantic regions. Compared to the spatial distribution of LF EAPE, which is also plotted in Fig. 8a, those regions are characterized by strong background temperature gradient and located just near or in the upstream of the action centers of LF EAPE. The LF eddy heat flux, as shown in Fig. 8b, peaks in the Bering Strait and the Greenland Sea, consistent with the distribution of LF EAPE in Fig. 8a. Moreover, the strongest LF eddy heat flux is near the action centers of LF EKE at $850 \mathrm{hPa}$ as well, which is also plotted in Fig. $8 \mathrm{~b}$ for comparison. In the North Atlantic, the LF eddy heat flux lies in the downstream region of LF EKE. In the North Pacific, the LF eddy heat flux is strongest to the northwest of LF EKE, which is also the downstream region of LF EKE given the background flow (i.e., Aleutian low).

The strong LF eddy heat flux and positive baroclinic generation suggest that local baroclinic instability may occur by extracting energy from the background flow to LF eddies as suggested by previous studies (e.g., Cai 2004), although the 
(a) $20 \mathrm{~N}-60 \mathrm{~N}$ AVE.

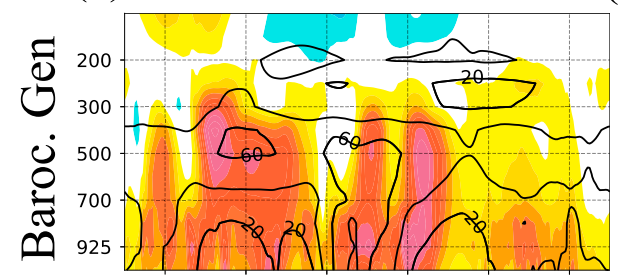

(c)

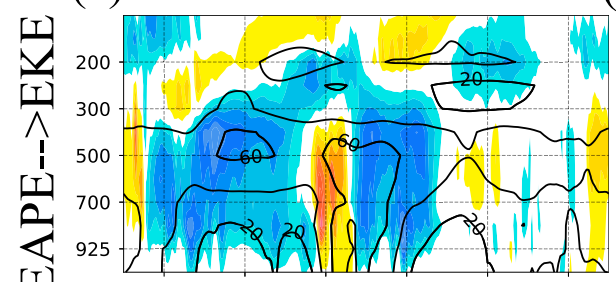

(e)

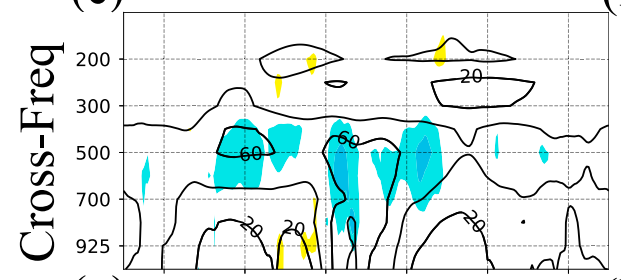

(g)

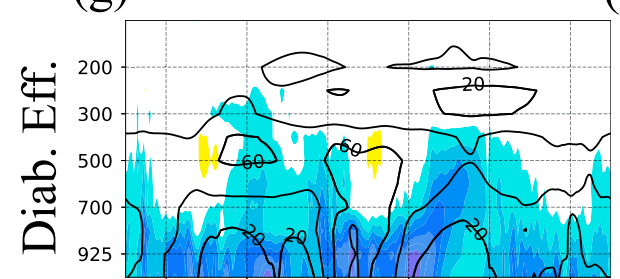

(i)

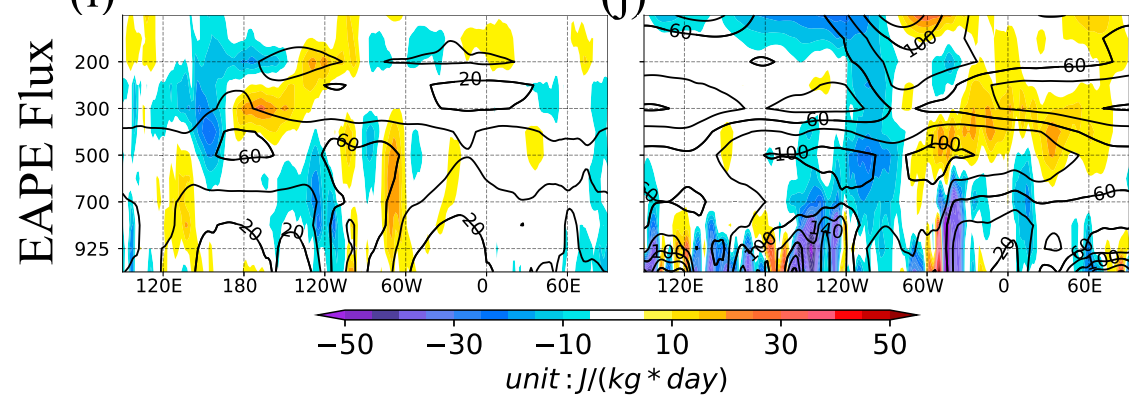

FIG. 6. Vertical-longitude distributions of each budget term for LF EAPE in the midlatitudes (averaged between $20^{\circ}$ and $60^{\circ} \mathrm{N}$ ) and high latitudes (averaged between $60^{\circ}$ and $70^{\circ} \mathrm{N}$ ), respectively: (a),(b) baroclinic generation term, (c),(d) baroclinic conversion term, (e),(f) cross-frequency eddy-eddy interaction term, $(\mathrm{g}),(\mathrm{h})$ diabatic effect term (computed as residual), and (i),(j) convergence of EAPE flux term. In all panels, distributions of LF EAPE in the middle and high latitudes are also plotted in contour for comparison, with contour interval of $20 \mathrm{~J} \mathrm{~kg}^{-1}$. baroclinic growth could be instantaneous, similar to the situation in Farrell (1982) or Plumb (1983). Here we estimate the growth rate of LF EAPE to compare with HF eddies. The growth rate $\sigma$ is defined as $\sigma=(1 / \mathrm{EAPE})(\partial \mathrm{EAPE} / \partial t)$ as in
Zhang and Stone (2010). Figures 9a and 9b show the composite of the evolution of growth rate in a life cycle of LF EAPE in the Barents Sea and Bering Sea, respectively, where the baroclinic generation is strongest. In Figs. 9c and 9d, composites of the 
(a) 700-1000 hPa AVE.

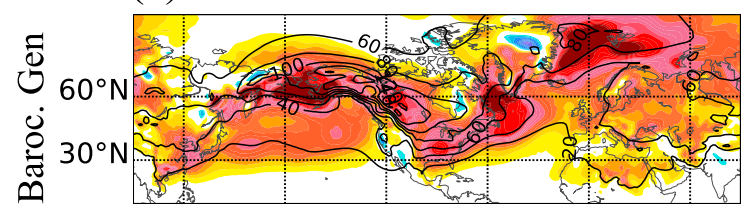

(b)

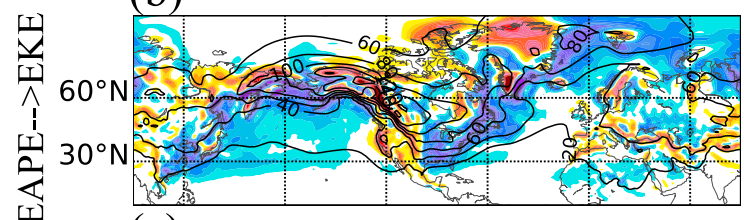

II

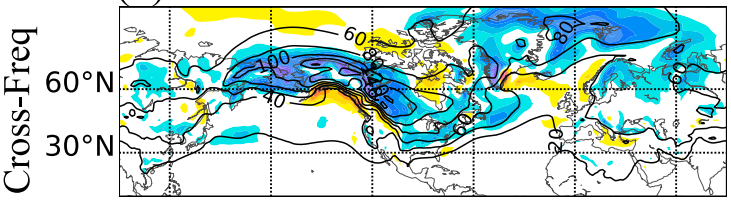

(d)

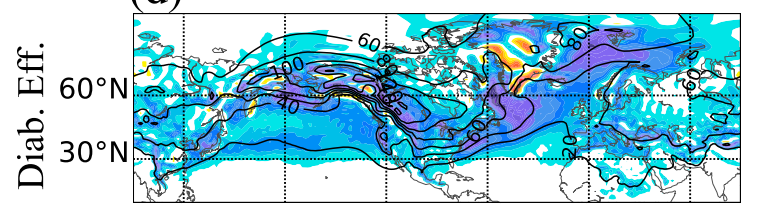

(e)

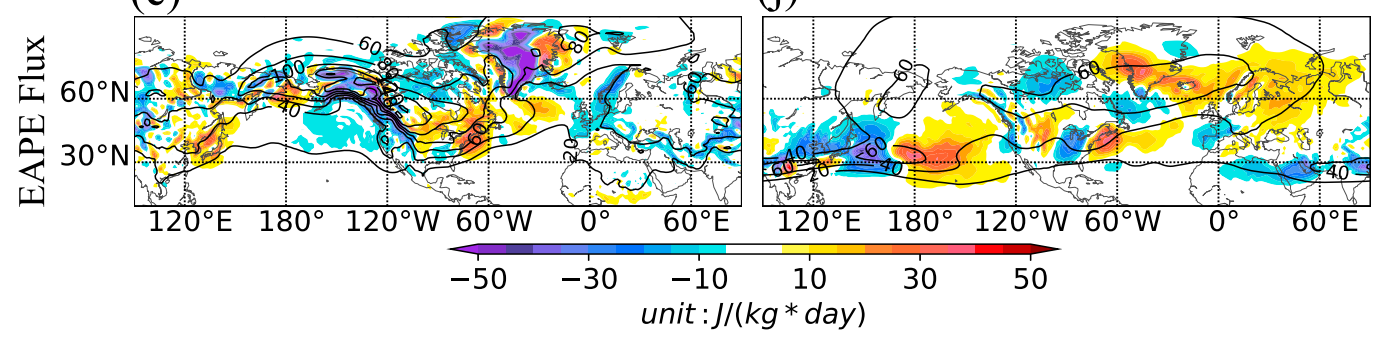

300-500 hPa AVE.

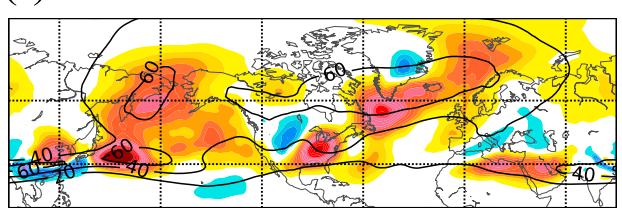

(g)

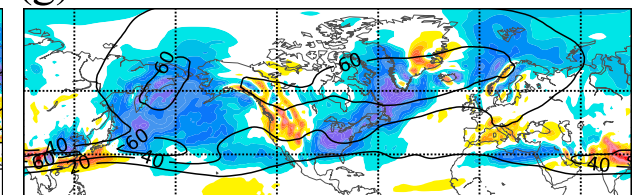

(h)

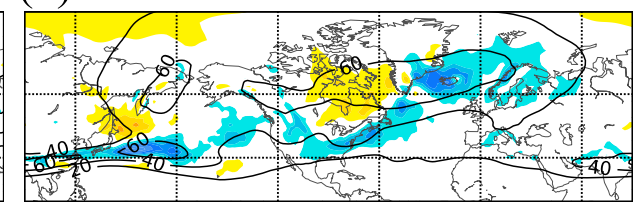

(i)

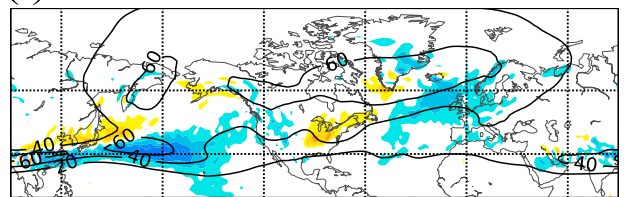

(j)

FIG. 7. Horizontal distributions of each budget term for LF EAPE averaged vertically between 700 and $1000 \mathrm{hPa}$ : (a) baroclinic generation term, (b) baroclinic conversion term, (c) cross-frequency eddy-eddy interaction term, (d) diabatic effect term (computed as residual), and (e) convergence of EAPE flux term. (f)-(j) As in (a)-(e), but for each budget term vertically between 300 and $500 \mathrm{hPa}$, respectively. In all panels, distributions of LF EAPE averaged vertically between 700 and 1000 or between 300 and $500 \mathrm{hPa}$ are also plotted in contour for comparison, with contour interval of $20 \mathrm{~J} \mathrm{~kg}^{-1}$.

evolution of growth rate for HF EAPE in North Atlantic and North Pacific, respectively, are also plotted for comparison. In the composite analysis, all events with the peak value of the area averaged EAPE greater than its one standard deviation are selected. The condition of continuous growing for five days is also used for the event selection of LF EAPE. For LF EAPE, the peak value and the averaged value of its growth rate in a typical life cycle is all evidently smaller than that of HF EAPE, which is consistent with the longer time scale of LF eddies. The analysis of LF EAPE growth rate and energy budget suggests that the slower-growing baroclinic generation can be one of the mechanisms for LF variabilities.

\section{b. On the relation between $L F E A P E$ and $L F E K E$}

Combined with previous energetic studies (e.g., Chang et al. 2002; Jiang et al. 2013), our LF EAPE budget analysis suggests a more comprehensive understanding of LF variabilities. LF EKE is maintained by the following processes:

$$
\frac{\partial K_{l}}{\partial t}=\underbrace{-\nabla_{3} \cdot\left(\mathbf{V}_{m} K_{l}+\Phi_{l} \mathbf{V}_{3 l}^{\prime}\right)}_{\text {EKE flux convergence }} \underbrace{-\mathbf{V}_{l}^{\prime} \cdot\left(\mathbf{V}_{3 l}^{\prime} \cdot \nabla_{3} \mathbf{V}_{m}\right)}_{\text {Barotropic conversion }} \underbrace{-\omega_{l}^{\prime} \alpha_{l}^{\prime}}_{\text {Baroclinic conversion Cross-frequency eddy-eddy interaction }} \underbrace{-\mathbf{V}_{l}^{\prime} \cdot\left(\mathbf{V}_{3}^{\prime} \cdot \nabla_{3} \mathbf{V}^{\prime}\right)_{l}^{\prime}}_{- \text {dissipation, }}+
$$


(a) Temperature gradient

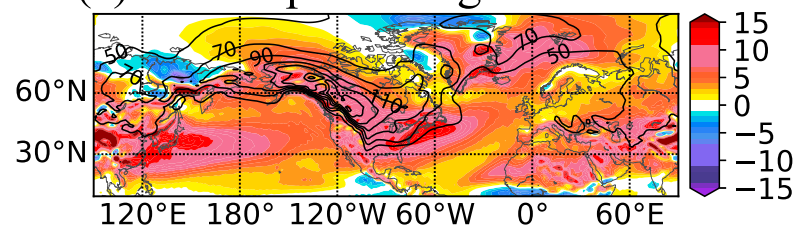

(b)

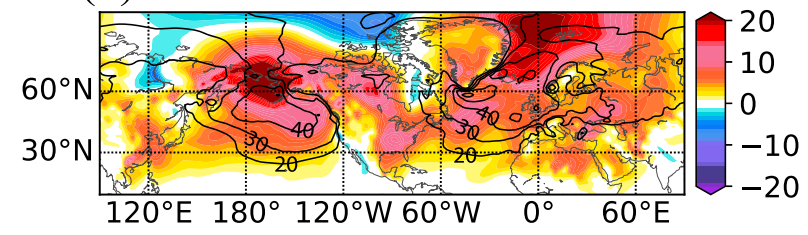

FIG. 8. Wintertime mean (a) meridional temperature gradient [K $\left.\left(10^{3} \mathrm{~km}\right)^{-1}\right]$ and (b) meridional heat flux of low-frequency eddies $\left(\mathrm{K} \mathrm{m} \mathrm{s}^{-1}\right)$ at $850 \mathrm{hPa}$. In (a) and (b), 850-hPa LF EAPE and LF EKE are also plotted in contours, respectively, with contour interval of $20 \mathrm{~J} \mathrm{~kg}^{-1}$ in (a) and $10 \mathrm{~J} \mathrm{~kg}^{-1}$ in (b).

in which the baroclinic conversion (BC) term denotes the conversion of energies between LF EAPE and LF EKE. As shown in Jiang et al. (2013), barotropic generation with the upper-level divergent flow in the jet exit regions and interactions between HF and LF eddies are two major barotropic processes that generate LF variabilities, especially over the eastern North Pacific and eastern North Atlantic. Our study shows that baroclinic generation, combined with the above barotropic processes, is another source for LF variabilities. The complete processes are summarized in Fig. 10. The LF EAPE produced by baroclinic generation can extend to upper levels in the western North Pacific and western North Atlantic, and is converted to LF EKE via warm air raising and cold air sinking. The converted LF EKE via baroclinic conversion is further advected downstream by the westerly flow, contributing to the strong upper-level LF EKE in the eastern ocean basins.

Although, similar to HF eddies, baroclinic conversion contributes positively to EKE, the relation between EAPE and EKE for LF eddies is more complicated. For HF eddies, as baroclinic instability is a dominant mechanism, HF EKE peaks in the downstream of HF EAPE with baroclinic conversion as its main energy source. For LF eddies, however, as shown in Fig. 8, LF EKE peaks almost in the upstream region of LF EAPE. Given that energies of LF eddies are from the mean flow via both barotropic and baroclinic generations and from the cross-frequency interaction with synoptic eddies especially for LF EKE, the causal relation between EKE and EAPE is not as straightforward as that for HF eddies. Over ocean basins, baroclinic generation, on one hand, contributes to the action centers of LF EKE in its downstream regions via baroclinic conversion. On the other hand, LF EKE also provides LF perturbations, which can trigger the baroclinic instability in the farther downstream coastal regions and tap the release of the background APE as suggested in Baggett and Lee (2015). The origins of LF perturbations can be from the tropical forcing (e.g., Baggett and Lee 2017) or from the internal extratropical dynamics with cross-frequency interactions between LF and HF eddies (e.g., Cai and van den Dool 1991; Jiang et al. 2013), the details of which in different regions need further investigation.

\section{Conclusions}

In this study, features and the maintenance of available potential energy of low-frequency eddies, which denotes low-frequency temperature fluctuations, have been studied. Our analysis shows that the wintertime LF EAPE, with greater amplitude than the extensively studied HF EAPE, exhibits distinct horizontal distributions and vertical structures. Compared to HF EAPE, which is strongest over midlatitude ocean basins, the action centers of LF EAPE are located in the populated continents in midlatitudes, as well as the subpolar regions. The LF EAPE in subpolar regions exhibits relatively shallow vertical structure, mostly confined near the surface.

By diagnosing the derived energy budget equation, the formation and maintenance of wintertime LF EAPE in Northern Hemisphere have been investigated (summarized in Fig. 10). Our analysis shows that with the strong background temperature gradient in subpolar regions (e.g., the coastal regions of the Greenland-Barents-Kara Seas), baroclinic generation is the major energy source of LF EAPE. The generated LF EAPE in the subpolar region is transported downstream and southward to midlatitude continents via background flow, which can result in persistent temperature fluctuations in Eurasia and North America. Near the surface, the generated LF EAPE, besides being damped locally by diabatic effect, is also dissipated by HF eddies via cross-frequency eddy-eddy interactions. Such complex energy budget in the lower troposphere helps explain the strong temperature variability over the continents in Eurasia region (e.g., Gu et al. 2018; TamarinBrodsky et al. 2019).

Our budget analysis, together with previous energetic studies of LF EKE, suggests multiple energy sources for LF variabilities. Our study shows that, similar to HF eddies, LF eddies also extract energy from the mean flow via baroclinic generation. They can be generated via local baroclinic instability, with slower growth rate thus with longer time scales. Over ocean basins, the baroclinic generation is strong in both lower and upper levels. The generated LF EAPE is greatly converted to LF EKE via vertical motions, which is further advected downstream by background wind and contributes to the strong LF EKE in upper levels. Therefore, combined with previous works (e.g., Cai and Mak 1990; Cai and van den Dool 1991; Jiang et al. 2013), baroclinic and barotropic generation with the mean flow and the cross-frequency interaction with synoptic eddies via vorticity flux all act as the main energy sources of LF eddies. The dynamics of LF variabilities are more complicated than those for HF eddies. Although the energetic studies identify the multiple energy sources for LF eddies, their detailed mechanisms, especially how the baroclinic process working together with the barotropic process affects the evolution of LF variabilities in different regions, require further investigation. 

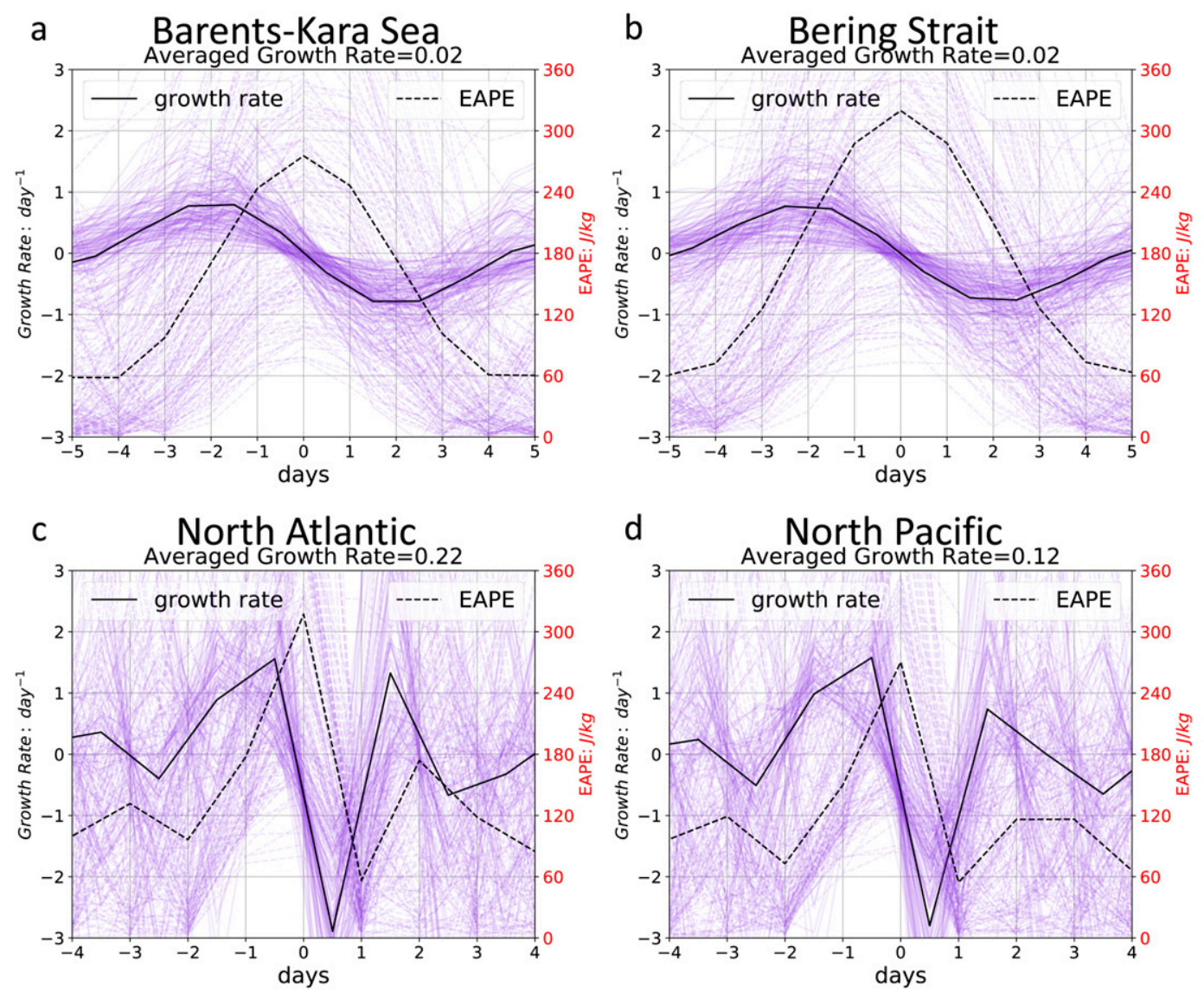

FIG. 9. Composite evolution of 500-hPa EAPE (dashed line) and EAPE growth rate (solid line) in a wintertime life cycle for LF EAPE averaged over a box region in the (a) Barents Sea $\left(30^{\circ}-40^{\circ} \mathrm{E}, 70^{\circ}-75^{\circ} \mathrm{N}\right)$ and (b) Bering Strait $\left(165^{\circ}-175^{\circ} \mathrm{W}, 60^{\circ}-65^{\circ} \mathrm{N}\right)$. (c),(d) As in (a) and (b), but for HF EAPE averaged over a box region in the North Atlantic $\left(50^{\circ}-55^{\circ} \mathrm{W}, 42^{\circ}-47^{\circ} \mathrm{N}\right)$ and North Pacific $\left(150^{\circ}-155^{\circ} \mathrm{E}, 42^{\circ}-47^{\circ} \mathrm{N}\right)$, respectively. All events with a peak value of the boxed averaged EAPE greater than its one standard deviation are selected for composite analysis. For LF EAPE, the condition of continuous growing for 5 days is added for event selection. Day 0 represents the peak day of EAPE during a cycle.

Acknowledgments. We thank three anonymous reviewers for providing insightful and constructive feedback, which greatly improved the quality of the paper. The reanalysis data of ERA-Interim are from http:/www.ecmwf.int/en/research/ climate-reanalysis/era-interim. The NCEP-NCAR reanalysis data can be downloaded from https://www.esrl.noaa.gov/ psd/data/gridded/data.ncep.reanalysis.pressure.html. This study was supported by the National Key Research and Development Program under Grant 2018YFC1506001, Strategic Priority Research Program of Chinese Academy of Sciences under Grant XDA20000000, and the National Natural Science Foundation of China under Grants 41675055 and 41621005.

\section{APPENDIX A}

\section{Derivation of the Budget of Available Potential Energy for Low-Frequency Eddies}

Here we provide the detailed derivation of the LF EAPE budget equation. We start from the thermodynamic equation

$$
\frac{\partial \theta}{\partial t}+\mathbf{V} \cdot \nabla \theta+\omega \frac{\partial \theta}{\partial p}=\frac{\left(\frac{p_{0}}{p}\right)^{R / c_{p}}}{c_{p}} Q
$$

where $\mathbf{V}$ denotes horizontal winds. The EAPE per unit mass is defined as in Orlanski and Katzfey (1991): 

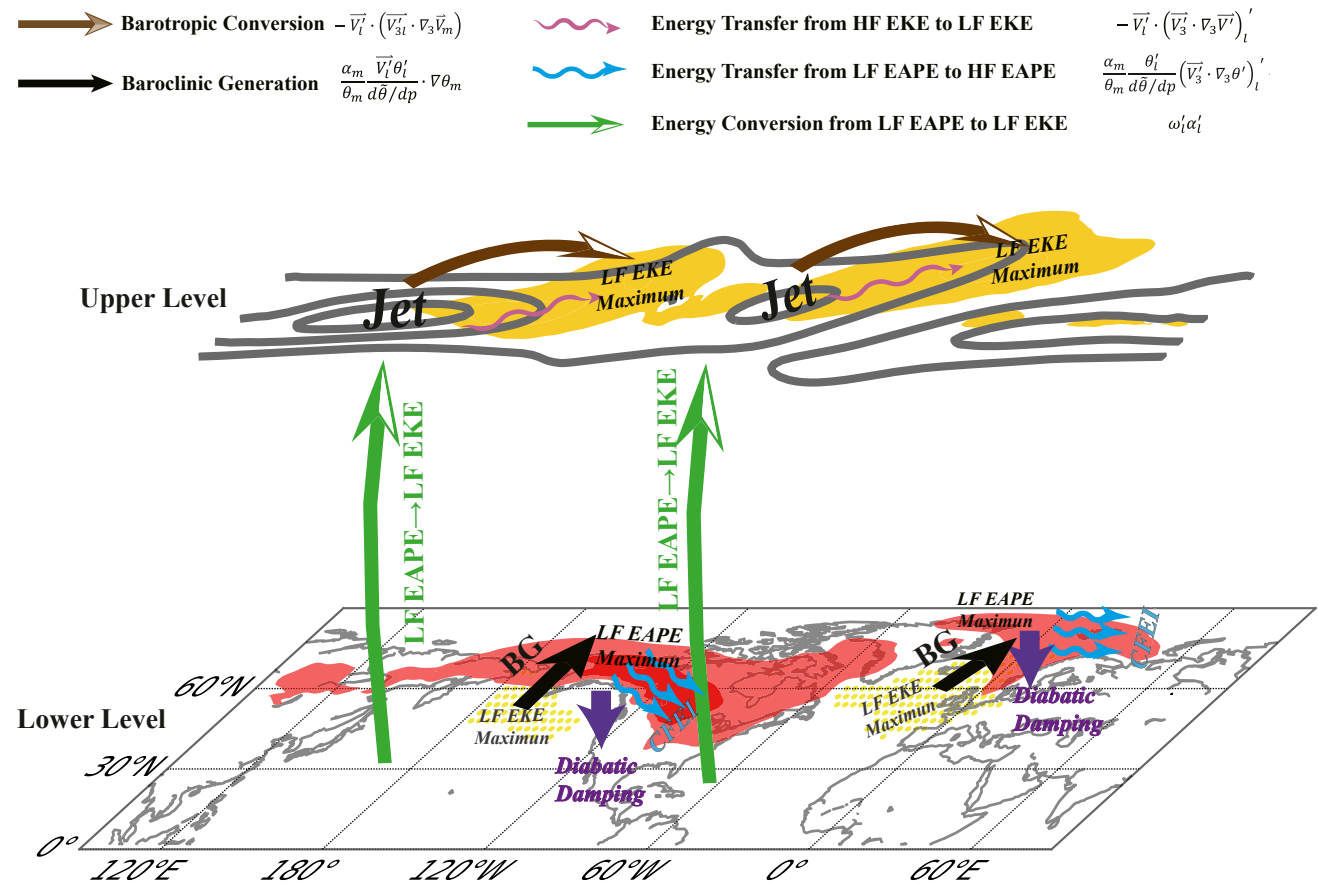

FIG. 10. A diagram summarizing the processes in LF EAPE and LF EKE energy budget. Shaded areas denote the action centers of LF EAPE in low levels (red) and LF EKE in upper levels (yellow). Arrows denote the peak location of each energy budget term. The inward (outward) direction of arrows to the action centers of LF energies indicate that the energy budget term acts as an energy source (sink) to the LF energy. Note that brown arrows in jet exits denote the barotropic process by divergence flow with energy converted from time-mean flow to lowfrequency EKE. The low-level action centers of LF EKE are also marked (yellow dotted) to demonstrate their relative position to the action centers of LF EAPE.

$$
A=-\frac{\alpha_{m}}{2 \theta_{m}} \frac{\theta^{2}}{\Gamma},
$$

where potential temperature is divided into the DJF mean and transient component $\left(\theta=\theta_{m}+\theta^{\prime}\right)$ and the stratification parameter $\Gamma=d \tilde{\theta} / d p$, with $\tilde{\theta}$ denoting the hemispheric and time averaged potential temperature. To obtain the budget equation of LF EAPE, we first rewrite Eq. (A1):

$$
\begin{aligned}
\frac{\partial\left(\theta_{m}+\theta^{\prime}\right)}{\partial t}= & -\left(\mathbf{V}_{m}+\mathbf{V}^{\prime}\right) \cdot \nabla\left(\theta_{m}+\theta^{\prime}\right) \\
& -\left(\omega_{m}+\omega^{\prime}\right) \frac{\partial\left(\theta_{m}+\theta^{\prime}\right)}{\partial p}+\frac{\left(\frac{p_{0}}{p}\right)^{R / c_{p}}}{c_{p}}\left(Q_{m}+Q^{\prime}\right) .
\end{aligned}
$$

The thermodynamic equation of the mean state can be obtained by taking a time average of Eq. (A3):

$$
\frac{\partial \theta_{m}}{\partial t}=-\mathbf{V}_{m} \cdot \nabla \theta_{m}-\omega_{m} \frac{\partial \theta_{m}}{\partial p}-\left(\mathbf{V}_{3}^{\prime} \cdot \nabla_{3} \theta^{\prime}\right)_{m}+\frac{\left(\frac{p_{0}}{p}\right)^{R / c_{p}}}{c_{p}} Q_{m},
$$

where the subscript $m$ denotes time average, $\mathbf{V}_{3}$ denotes the three-dimensional winds vector, and $\nabla_{3}$ denotes the gradient in the horizontal and vertical directions. By subtracting Eq. (A4) from Eq. (A3), we can obtain the thermodynamic equation for the transient eddy:

$$
\begin{aligned}
\frac{\partial \theta^{\prime}}{\partial t}= & -\mathbf{V}_{m} \cdot \nabla \theta^{\prime}-\mathbf{V}^{\prime} \cdot \nabla \theta_{m}-\omega_{m} \frac{\partial \theta^{\prime}}{\partial p}-\omega^{\prime} \frac{\partial \theta_{m}}{\partial p} \\
& -\left(\mathbf{V}_{3}^{\prime} \cdot \nabla_{3} \theta^{\prime}\right)^{\prime}+\frac{\left(\frac{p_{0}}{p}\right)^{R / c_{p}}}{c_{p}} Q^{\prime},
\end{aligned}
$$

where the prime denotes a transient variable. The EAPE budget can be obtained by multiplying Eq. (A5) by $-\left(\alpha_{m} / \theta_{m}\right)\left(\theta^{\prime} / \Gamma\right)$ :

$$
\begin{aligned}
\frac{\partial A}{\partial t}= & -\mathbf{V}_{3 m} \cdot \nabla_{3} A+\frac{\alpha_{m}}{\theta_{m}} \frac{\mathbf{V}^{\prime} \theta^{\prime}}{\Gamma} \cdot \nabla \theta_{m}+\omega^{\prime} \alpha^{\prime} \\
& +\frac{\alpha_{m}}{\theta_{m}} \frac{\theta^{\prime}}{\Gamma}\left(\mathbf{V}_{3}^{\prime} \cdot \nabla_{3} \theta^{\prime}\right)^{\prime}-\frac{\alpha_{m}}{\theta_{m} c_{p}} \frac{\theta^{\prime} Q^{\prime}\left(\frac{P_{0}}{p}\right)^{R / c_{p}}}{\Gamma},
\end{aligned}
$$

where $\alpha^{\prime}$ is the transient part of the inverse of density. With the assumption that the mean wind is almost nondivergent, which is shown to be reasonable for extratropical large-scale motions (Orlanski and Katzfey 1991; Chang et al. 2002), the advection 
of EAPE [first term on the right-hand side of Eq. (A6)] can be written in the form of EAPE flux convergence, following the previous energetic studies (Orlanski and Katzfey 1991; Jiang et al. 2013). Then the EAPE budget equation becomes

$$
\frac{\partial A}{\partial t}=\underbrace{-\nabla_{3} \cdot\left(\mathbf{V}_{3 m} A\right)}_{\text {EAPE flux convergence }}+\underbrace{\frac{\alpha_{m}}{\theta_{m}} \frac{\mathbf{V}^{\prime} \theta^{\prime}}{\Gamma} \cdot \nabla \theta_{m}}_{\text {Baroclinic generation }}+\underbrace{\omega^{\prime} \alpha^{\prime}}_{\text {Baroclinic conversion }}+\underbrace{\frac{\alpha_{m}}{\theta_{m}} \frac{\theta^{\prime}}{\Gamma}\left(\mathbf{V}_{3}^{\prime} \cdot \nabla_{3} \theta^{\prime}\right)^{\prime}}_{\text {Cross-frequency eddy-eddy interaction }}-\underbrace{\frac{\alpha_{m}}{\theta_{m} c_{p}} \frac{\theta^{\prime} Q^{\prime}\left(\frac{P_{0}}{p}\right)^{R / c_{p}}}{\Gamma}}_{\text {Diabatic heating }} .
$$

To derive the LF EAPE budget, we follow the method in previous studies (e.g., Jiang and Deng 2011; Jiang et al. 2013; Nie et al. 2013; Lu 2017) and apply the 10-day low-pass Lanczos filter to each term in Eq. (A5) after removing the seasonal cycle, which is defined as the first four Fourier harmonics of 37 years' daily climatology of each term in Eq. (A5). The thermodynamic equation of LF transient eddy can be obtained:

$$
\frac{\partial \theta_{l}^{\prime}}{\partial t}=-\mathbf{V}_{m} \cdot \nabla \theta_{l}^{\prime}-\mathbf{V}_{l}^{\prime} \cdot \nabla \theta_{m}-\omega_{m} \frac{\partial \theta_{l}^{\prime}}{\partial p}-\omega_{l}^{\prime} \frac{\partial \theta_{m}}{\partial p}-\left(\mathbf{V}_{3}^{\prime} \cdot \nabla_{3} \theta^{\prime}\right)_{l}^{\prime}+\frac{\left(\frac{p_{0}}{p}\right)^{R / c_{p}}}{c_{p}} Q_{l}^{\prime}
$$

where ()$_{l}^{\prime}$ denotes the low-frequency component with seasonal cycle removed. Note that the tendency of the LF slowly varying potential temperature is usually smaller than the tendency of $\mathrm{HF}$ eddies. The forcing terms on the rhs of Eq. (A8) are more balanced for LF perturbations. Multiplying Eq. (A8) by $-\left[\left(\alpha_{m} / \theta_{m}\right)\left(\theta_{l}^{\prime} / \Gamma\right)\right]$, we obtain the final form of the budget equation of LF EAPE:

$$
\frac{\partial A_{l}}{\partial t}=\underbrace{-\nabla_{3} \cdot\left(\mathbf{V}_{3 m} A_{l}\right)}_{\text {EAPE flux convergence }}+\underbrace{\frac{\alpha_{m}}{\theta_{m}} \frac{\mathbf{V}_{l}^{\prime} \theta_{l}^{\prime}}{\Gamma} \cdot \nabla \theta_{m}}_{\text {Baroclinic generation }}+\underbrace{\omega_{l}^{\prime} \alpha_{l}^{\prime}}_{\text {Baroclinic conversion }}+\underbrace{\frac{\alpha_{m}}{\theta_{m}} \frac{\theta_{l}^{\prime}}{\Gamma}\left(\mathbf{V}_{3}^{\prime} \cdot \nabla_{3} \theta^{\prime}\right)_{l}^{\prime}}_{\text {Cross-frequency eddy interactions }}-\underbrace{\frac{\alpha_{m}}{\theta_{m} c_{p}} \frac{\theta_{l}^{\prime} Q_{l}^{\prime}\left(\frac{P_{0}}{p}\right)^{R / c_{p}}}{\Gamma}}_{\text {Diabatic heating }} .
$$

\section{APPENDIX B}

\section{EAPE Budget for 10-30-Day and 30-90-Day Time Scales}

The energy budget of EAPE for eddies with time scales 1030 and 30-90 days are also derived and investigated. The EAPE for eddies with the two time scales are defined as

$$
A_{\text {in }}=-\frac{\alpha_{m}}{2 \theta_{m}} \frac{\theta_{\text {in }}^{\prime 2}}{\Gamma},
$$

$$
A_{\mathrm{lo}}=-\frac{\alpha_{m}}{2 \theta_{m}} \frac{\theta_{\mathrm{lo}}^{\prime 2}}{\Gamma},
$$

where subscripts "in" and "lo" represent eddy components with 10-30- and 30-90-day time scales, respectively. The other variables are all defined the same as in section 2. Following similar derivation to that in appendix $\mathrm{A}$, we can obtain the budget equation for $A_{\text {in }}$ and $A_{\mathrm{lo}}$ :

$$
\begin{aligned}
& \frac{\partial A_{\mathrm{in}}}{\partial t}=\underbrace{-\nabla_{3} \cdot\left(\mathbf{V}_{3 m} A_{\text {in }}\right)}_{\text {EAPE flux convergence }}+\underbrace{\frac{\alpha_{m}}{\theta_{m}} \frac{\mathbf{V}_{\mathrm{in}}^{\prime} \theta_{\mathrm{in}}^{\prime}}{\Gamma} \cdot \nabla \theta_{m}}_{\text {Baroclinic generation }}+\underbrace{\omega_{\mathrm{in}}^{\prime} \alpha_{\mathrm{in}}^{\prime}}_{\text {Baroclinic conversion }}+\underbrace{\frac{\alpha_{m}}{\theta_{m}} \frac{\theta_{\mathrm{in}}^{\prime}}{\Gamma}\left(\mathbf{V}_{3}^{\prime} \cdot \nabla_{3} \theta^{\prime}\right)_{\text {in }}^{\prime}}_{\text {Cross-frequency eddy interactions }}-\underbrace{\frac{\alpha_{m}}{\theta_{m} c_{p}} \frac{\theta_{\mathrm{in}}^{\prime} Q_{\mathrm{in}}^{\prime}\left(\frac{P_{0}}{p}\right)^{R / c_{p}}}{\Gamma}}_{\text {Diabatic heating }} \\
& \frac{\partial A_{\mathrm{lo}}}{\partial t}=\underbrace{-\nabla_{3} \cdot\left(\mathbf{V}_{3 m} A_{\mathrm{lo}}\right)}_{\text {EAPE flux convergence }}+\underbrace{\frac{\alpha_{m}}{\theta_{m}} \frac{\mathbf{V}_{\mathrm{lo}}^{\prime} \theta_{\mathrm{lo}}^{\prime}}{\Gamma} \cdot \nabla \theta_{m}}_{\text {Baroclinic generation }}+\underbrace{\omega_{\mathrm{lo}}^{\prime} \alpha_{\mathrm{lo}}^{\prime}}_{\text {Baroclinic conversion }}+\underbrace{\frac{\alpha_{m}}{\theta_{m}} \frac{\theta_{\mathrm{lo}}^{\prime}}{\Gamma}\left(\mathbf{V}_{3}^{\prime} \cdot \nabla_{3} \theta^{\prime}\right)_{\mathrm{lo}}^{\prime}}_{\text {Cross-frequency eddy-eddy interactions }}-\underbrace{\frac{\alpha_{m}}{\theta_{m} c_{p}} \frac{\theta_{\mathrm{lo}}^{\prime} Q_{\mathrm{lo}}^{\prime}\left(\frac{P_{0}}{p}\right)^{R / c_{p}}}{\Gamma}}_{\text {Diabatic heating }} .
\end{aligned}
$$



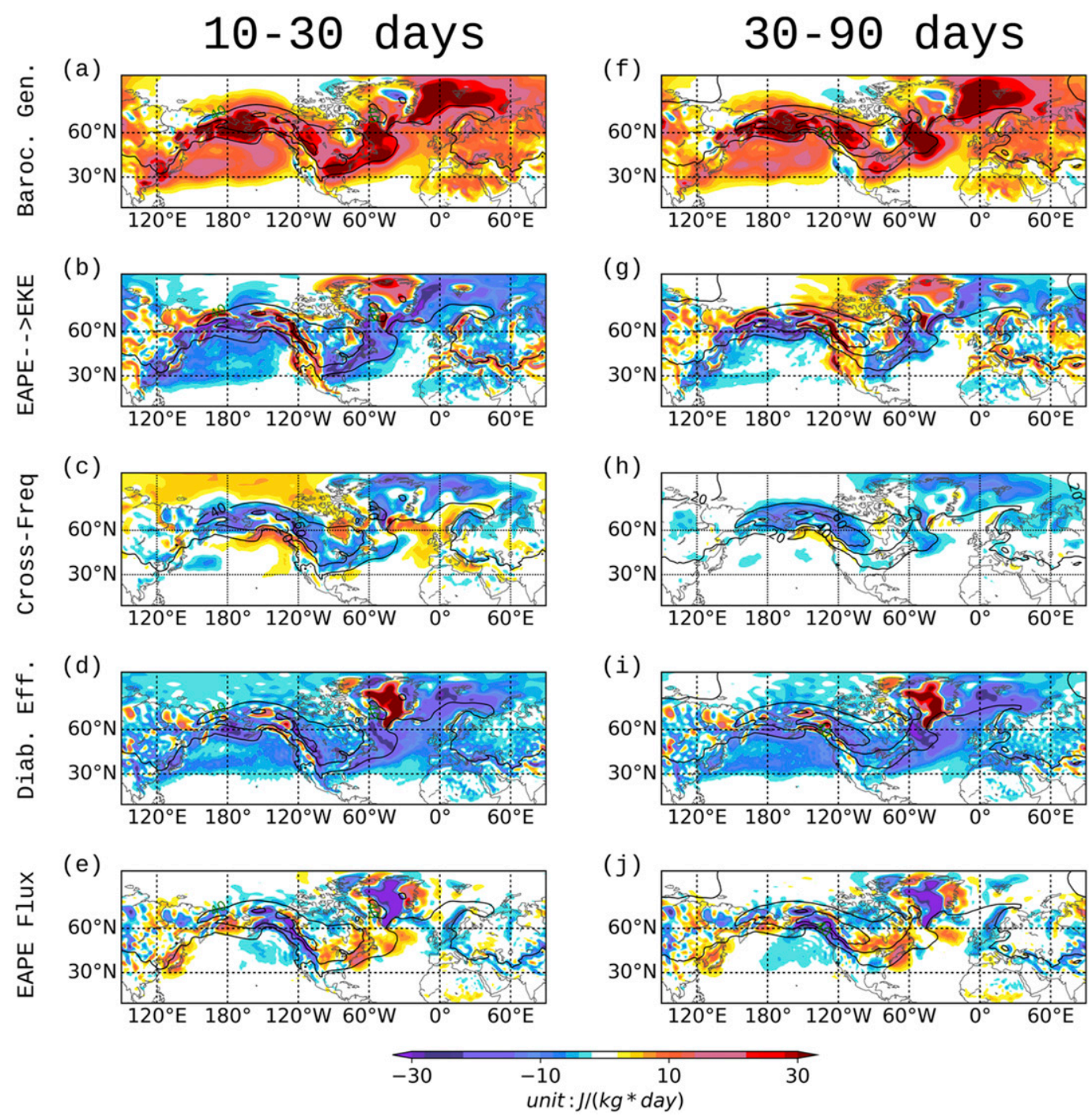

FIG. B1. Horizontal distributions of each budget term for EAPE averaged vertically between 700 and $1000 \mathrm{hPa}$ for eddies with a 10-30-day time scale: (a) baroclinic generation term, (b) baroclinic conversion term, (c) crossfrequency eddy-eddy interaction term, (d) diabatic effect term (computed as residual), and (e) convergence of EAPE flux term. (f)-(j) As in (a)-(e), but for each EAPE budget term for eddies with 30-90-day time scale, respectively. In all panels, distributions of EAPE averaged vertically between 700 and $1000 \mathrm{hPa}$ are also plotted in contour for comparison, with contour interval of $20 \mathrm{~J} \mathrm{~kg}^{-1}$.

Spatial distributions of each energy budget term in Eqs. (B3) and (B4) are plotted in Figs. B1 and B2. Given that the energy budget of total LF EAPE exhibits different balance in the lower and upper troposphere, the energy budget terms are also averaged over the lower and upper levels. Figure 11 shows the lower-tropospheric (700-1000 hPa) averaged EAPE budget for 10-30- and 30-90-day time scales. Although previous studies suggest different barotropic mechanisms for 10-30- and 30-90-day variabilities (Blackmon et al. 1984a,b; Jiang et al. 2013), the EAPE energy budget terms show similar spatial distributions and thus similar energy balance in the two time scales in lower troposphere. The energy produced by baroclinic generation (BG; Figs. B1a,f) is mostly balanced by the energy dissipation by cross-frequency eddy-eddy interaction (CFEI; Figs. B1b,g) and the energy damping by diabatic forcing (Figs. $\mathrm{B} 1 \mathrm{~d}, \mathrm{i})$. The baroclinic conversion (BC) term for the two time scales also shows similar spatial patterns, with stronger magnitude for 10-30-day time scale acting to convert EAPE to EKE for variabilities in 10-30-day time scale. The major difference lies in the CFEI term. In addition to the dissipation effect in most of the continents for 10-30- and 30-90-day variabilities, cross-frequency eddy-eddy interaction acts to 

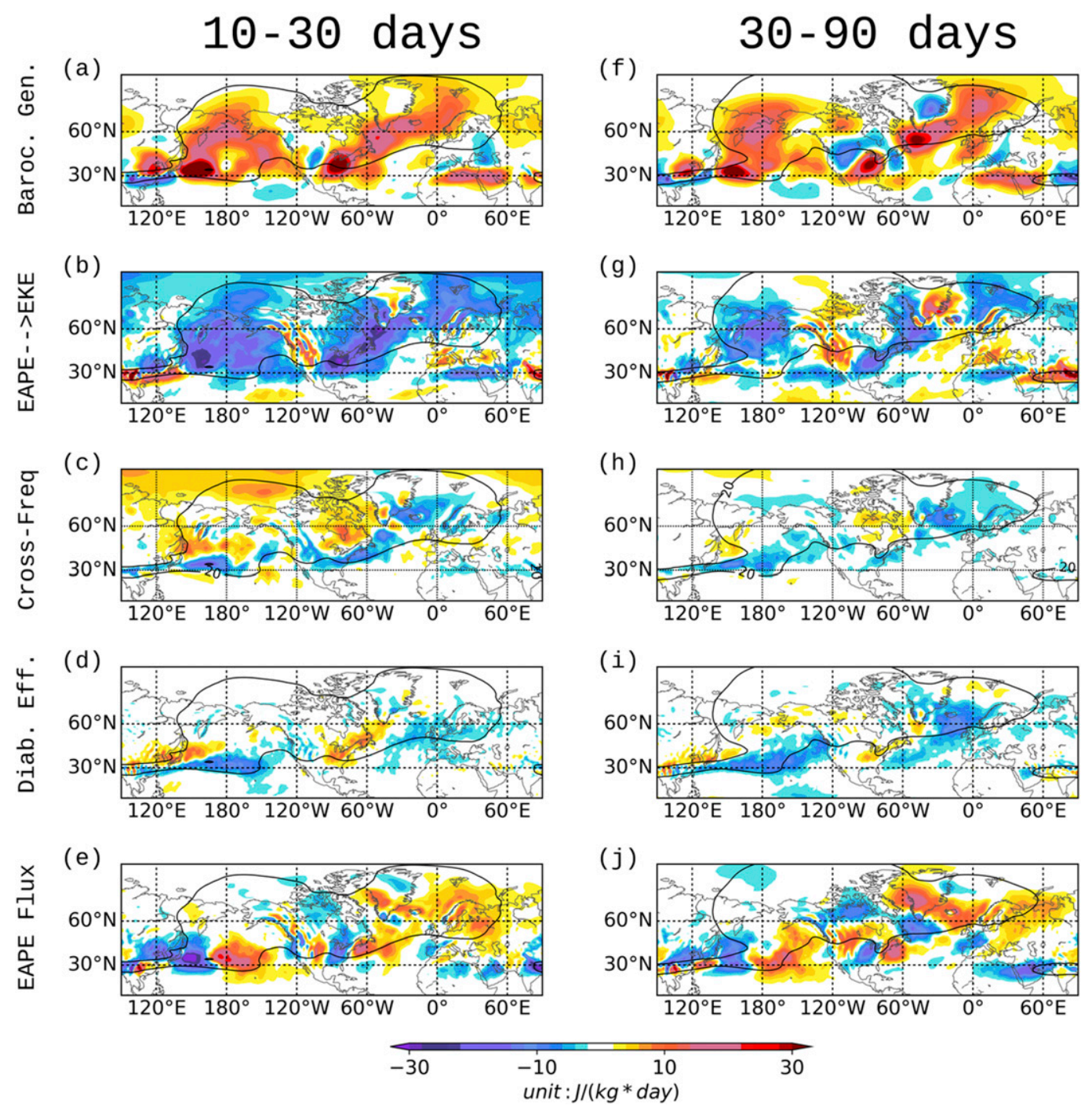

FIG. B2. As in Fig. B1, but vertically averaged between 300 and $500 \mathrm{hPa}$.

generate the 10-30-day variability in polar regions from the East Siberia Sea extending eastward to the Beaufort Sea.

The upper-tropospheric averaged (300-500 hPa) energy budget for 10-30- and 30-90-day time scales is also plotted in Fig. B2. The spatial distributions of each energy term also show roughly similar energy balance in the two time scales, although more differences are exhibited compared with those in lower troposphere. The strongest baroclinic generation (Figs. B2a,f) for the two time scales is all in the western North Pacific, Bering Strait, and North Atlantic, which is all greatly balanced by the baroclinic conversion term (Figs. B2b,g). However, for 10-30-day time scales, the baroclinic conversion is stronger and expands the whole North Pacific and North Atlantic basins. For 30-90-day time scale, the baroclinic conversion term is weaker, and thus the baroclinic generation is also strongly balanced by diabatic effects (Fig. B2i) and cross-frequency eddy-eddy interaction (Fig. B2h).
Another difference of the energy budget between the two time scales also lies in the cross-frequency term. A positive CFEI term is also observed in polar regions and midlatitude continents for 10-30-day time scales in contrast to its dissipation effect for 30-90-day time scales, suggesting possible different baroclinic mechanisms for variabilities over the two time scales.

\section{REFERENCES}

Baggett, C., and S. Lee, 2015: Arctic warming induced by tropically forced tapping of available potential energy and the role of the planetary-scale waves. J. Atmos. Sci., 72, 1562-1568, https:// doi.org/10.1175/JAS-D-14-0334.1.

— , and - 2017: An identification of the mechanisms that lead to Arctic warming during planetary-scale and synoptic-scale wave life cycles. J. Atmos. Sci., 74, 1859-1877, https://doi.org/ 10.1175/JAS-D-16-0156.1. 
Blackmon, M. L., Y.-H. Lee, and J. M. Wallace, 1984a: Horizontal structure of $500 \mathrm{mb}$ height fluctuations with long, intermediate and short time scales. J. Atmos. Sci., 41, 961-980, https://doi.org/ 10.1175/1520-0469(1984)041<0961:HSOMHF>2.0.CO;2.

$\_,-\ldots$, _, and H.-H. Hsu, 1984b: Time variation of $500 \mathrm{mb}$ height fluctuations with long, intermediate and short time scales as deduced from lag-correlation statistics. J. Atmos. Sci., 41, 981-991, https:// doi.org/10.1175/1520-0469(1984)041<0981:TVOMHF>2.0.CO;2.

Cai, M., 1992: A physical interpretation for the stability property of a localized disturbance in a deformation flow. J. Atmos. Sci., 49, 2177-2182, https://doi.org/10.1175/1520-0469(1992)049<2177: APIFTS $>2.0 . \mathrm{CO} ; 2$.

- 2004: Local instability dynamics of storm tracks. Observation, Theory and Modeling of Atmospheric Variability, World Scientific Series on Asia-Pacific Weather and Climate, Vol. 3, World Scientific, 3-38, https://doi.org/10.1142/5431.

_ synoptic-scale waves. J. Atmos. Sci., 47, 2953-2968, https:// doi.org/10.1175/1520-0469(1990)047<2953:SRBPAS > 2.0.CO;2.

__ and H. M. van den Dool, 1991: Low-frequency waves and traveling storm tracks. Part I: Barotropic component. J. Atmos. Sci., 48, 1420-1436, https://doi.org/10.1175/1520-0469(1991)048<1420: LFWATS $>2.0 . \mathrm{CO} ; 2$.

_- S. Yang, H. van den Dool, and V. Kousky, 2007: Dynamical implications of the orientation of atmospheric eddies: A local energetics perspective. Tellus, 59A, 127-140, https://doi.org/ 10.1111/j.1600-0870.2006.00213.x.

Chang, E. K. M., and I. Orlanski, 1993: On the dynamics of a storm track. J. Atmos. Sci., 50, 999-1015, https://doi.org/10.1175/ 1520-0469(1993)050<0999:OTDOAS > 2.0.CO;2.

- S. Lee, and K. L. Swanson, 2002: Storm track dynamics. J. Climate, 15, 2163-2183, https://doi.org/10.1175/1520-0442(2002) 015<02163:STD $>2.0 . C O ; 2$.

Charney, J. G., 1947: The dynamics of long waves in a baroclinic westerly current. J. Meteor., 4, 136-162, https://doi.org/10.1175/ 1520-0469(1947)004<0136:TDOLWI >2.0.CO;2.

Coumou, D., V. Petoukhov, S. Rahmstorf, S. Petri, and H. J. Schellnhuber, 2014: Quasi-resonant circulation regimes and hemispheric synchronization of extreme weather in boreal summer. Proc. Natl. Acad. Sci. USA, 111, 12331-12336, https://doi.org/10.1073/pnas.1412797111.

Dee, D. P., and Coauthors, 2011: The ERA-Interim reanalysis: Configuration and performance of the data assimilation system. Quart. J. Roy. Meteor. Soc., 137, 553-597, https://doi.org/ 10.1002/qj.828.

Deng, Y., and M. Mak, 2005: An idealized model study relevant to the dynamics of the midwinter minimum of the Pacific storm track. J. Atmos. Sci., 62, 1209-1225, https://doi.org/10.1175/JAS3400.1.

Eady, E. T., 1949: Long waves and cyclone waves. Tellus, 1A, $33-$ 52, https://doi.org/10.1111/j.2153-3490.1949.tb01265.x.

Farrell, B., 1982: The initial growth of disturbances in a baroclinic flow. J. Atmos. Sci., 39, 1663-1686, https://doi.org/10.1175/ 1520-0469(1982)039<1663:TIGODI > 2.0.CO;2.

Gu, S., Y. Zhang, Q. Wu, and X. Q. Yang, 2018: The linkage between Arctic sea ice and midlatitude weather: In the perspective of energy. J. Geophys. Res. Atmos., 123, 11 53611 550, https://doi.org/10.1029/2018JD028743.

Gutowski, W. J., L. E. Branscome, and D. A. Stewart, 1989: Mean flow adjustment during life cycles of baroclinic waves. J. Atmos. Sci., 46, 1724-1737, https://doi.org/10.1175/1520-0469(1989) 046<1724:MFADLC $>2.0$. CO;2.

Hoskins, B. J., and D. J. Karoly, 1981: The steady linear response of a spherical atmosphere to thermal and orographic forcing.
J. Atmos. Sci., 38, 1179-1196, https://doi.org/10.1175/15200469(1981)038<1179:TSLROA > 2.0.CO;2.

, and K. I. Hodges, 2002: New perspectives on the Northern Hemisphere winter storm tracks. J. Atmos. Sci, 59, 1041-1061, https:// doi.org/10.1175/1520-0469(2002)059<1041:NPOTNH >2.0.CO;2.

— storm tracks. Part I: Seasons. J. Climate, 32, 1743-1760, https:// doi.org/10.1175/JCLI-D-17-0870.1.

_ I. N. James, and G. H. White, 1983: The shape, propagation and mean-flow interaction of large-scale weather systems. J. Atmos. Sci., 40, 1595-1612, https://doi.org/10.1175/15200469(1983)040<1595:TSPAMF $>2.0 . \mathrm{CO} ; 2$.

Jiang, T., and Y. Deng, 2011: Downstream modulation of North Pacific atmospheric river activity by East Asian cold surges. Geophys. Res. Lett., 38, L20807, https://doi.org/10.1029/2011GL049462.

,$- \ldots$, and W. Li, 2013: Local kinetic energy budget of highfrequency and intermediate-frequency eddies: Winter climatology and interannual variability. Climate Dyn., 41, 961-976, https://doi.org/10.1007/s00382-013-1684-1.

— K. K. Evans, Y. Deng, and X. Dong, 2014: Intermediate frequency atmospheric disturbances: A dynamical bridge connecting western U.S. extreme precipitation with East Asian cold surges. J. Geophys. Res. Atmos., 119, 3723-3735, https:// doi.org/10.1002/2013JD021209.

Lau, N.-C., and E. O. Holopainen, 1984: Transient eddy forcing of the time-mean flow as identified by geopotential tendencies. J. Atmos. Sci., 41, 313-328, https://doi.org/10.1175/1520-0469(1984) 041<0313:TEFOTT > 2.0.CO;2.

Lorenz, E. N., 1955: Available potential energy and the maintenance of the general circulation. Tellus, 7, 157-167, https:// doi.org/10.3402/tellusa.v7i2.8796.

Lu, Y., 2017: Dynamical footprints of aerosols in extratropical atmospheric disturbances and circulation: A modeling analysis. Ph.D. thesis, Georgia Institute of Technology, $144 \mathrm{pp}$.

Nie, Y., Y. Zhang, X.-Q. Yang, and G. Chen, 2013: Baroclinic anomalies associated with the Southern Hemisphere annular mode: Roles of synoptic and low-frequency eddies. Geophys. Res. Lett., 40, 2361-2366, https://doi.org/10.1002/grl.50396.

Oort, A. H., and J. P. Peixoto, 1983: Global angular momentum and energy balance requirements from observations. Advances in Geophysics, Vol. 25, Academic Press, 355-490, https://doi.org/ 10.1016/S0065-2687(08)60177-6.

Orlanski, I., and J. Katzfey, 1991: The life cycle of a cyclone wave in the southern hemisphere. Part I: Eddy energy budget. J. Atmos. Sci., 48, 1972-1998, https://doi.org/10.1175/1520-0469(1991)048<1972: TLCOAC $>2.0$. CO;2.

Peixoto, J., and A. Oort, 1992: Physics of Climate. American Institute of Physics, 520 pp.

Petoukhov, V., S. Petri, S. Rahmstorf, D. Coumou, K. Kornhuber, and H. J. Schellnhuber, 2016: Role of quasiresonant planetary wave dynamics in recent boreal spring-to-autumn extreme events. Proc. Natl. Acad. Sci. USA, 113, 6862-6867, https:// doi.org/10.1073/pnas.1606300113.

Plumb, R. A., 1983: A new look at the energy cycle. J. Atmos. Sci., 40, 1669-1688, https://doi.org/10.1175/1520-0469(1983)040<1669: ANLATE $>2.0 . \mathrm{CO} ; 2$.

Sardeshmukh, P. D., and B. J. Hoskins, 1988: The generation of global rotational flow by steady idealized tropical divergence. J. Atmos. Sci., 45, 1228-1251, https://doi.org/10.1175/15200469(1988)045<1228:TGOGRF $>2.0$. CO;2.

Schneider, T., 2006: The general circulation of the atmosphere. Annu. Rev. Earth Planet. Sci., 34, 655-688, https://doi.org/ 10.1146/annurev.earth.34.031405.125144. 
Simmons, A. J., and B. J. Hoskins, 1978: The life cycles of some nonlinear baroclinic waves. J. Atmos. Sci., 35, 414-432, https:// doi.org/10.1175/1520-0469(1978)035<0414:TLCOSN>2.0.CO;2.

_- J. M. Wallace, and G. W. Branstator, 1983: Barotropic wave propagation and instability, and atmospheric teleconnection patterns. J. Atmos. Sci., 40, 1363-1392, https://doi.org/10.1175/ 1520-0469(1983)040<1363:BWPAIA > 2.0.CO;2.

Song, L., L. Wang, W. Chen, and Y. Zhang, 2016: Intraseasonal variation of the strength of the East Asian trough and its climatic impacts in boreal winter. J. Climate, 29, 2557-2577, https://doi.org/10.1175/JCLI-D-14-00834.1.

Stone, P. H., 1978: Baroclinic adjustment. J. Atmos. Sci., 35, 561-571, https://doi.org/10.1175/1520-0469(1978)035<0561:BA >2.0.CO;2.

Swanson, K., and R. T. Pierrehumbert, 1997: Lower-tropospheric heat transport in the Pacific storm track. J. Atmos. Sci., 54, 1533-1543, https://doi.org/10.1175/1520-0469(1997)054<1533: LTHTIT $>2.0 . \mathrm{CO} ; 2$.

Tamarin-Brodsky, T., K. Hodges, B. J. Hoskins, and T. G. Shepherd, 2019: A dynamical perspective on atmospheric temperature variability and its response to climate change. J. Climate, 32, 1707-1724, https://doi.org/10.1175/JCLI-D-180462.1.

Trenberth, K. E., 1991: Storm tracks in the Southern Hemisphere. J. Atmos. Sci., 48, 2159-2178, https://doi.org/10.1175/15200469(1991)048<2159:STITSH >2.0.CO;2.
Xie, Z., R. X. Black, and Y. Deng, 2019: Planetary and synopticscale dynamic control of extreme cold wave patterns over the United States. Climate Dyn., 53, 1477-1495, https://doi.org/ 10.1007/s00382-019-04683-7.

Yoo, C., S. Lee, and S. B. Feldstein, 2012a: Arctic response to an MJO-like tropical heating in an idealized GCM. J. Atmos. Sci., 69, 2379-2393, https://doi.org/10.1175/JAS-D-11-0261.1.

$\ldots, \ldots$, and 2012b: Mechanisms of Arctic surface air temperature change in response to the Madden-Julian oscillation. J. Climate, 25, 5777-5790, https://doi.org/10.1175/JCLID-11-00566.1.

Zhang, Y., and P. H. Stone, 2010: Baroclinic eddy equilibration under specified seasonal forcing. J. Atmos. Sci., 67, 2632-2648, https://doi.org/10.1175/2010JAS3392.1.

$\longrightarrow$, and - 2011: Baroclinic adjustment in an atmosphereocean thermally coupled model: The role of the boundary layer processes. J. Atmos. Sci., 68, 2710-2730, https://doi.org/ 10.1175/JAS-D-11-078.1.

_- X.-Q. Yang, and Y. Nie, 2012: Annular mode-like variation in a multilayer quasigeostrophic model. J. Atmos. Sci., 69, 2940-2958, https://doi.org/10.1175/JAS-D-11-0214.1.

Zurita-Gotor, P., and R. Lindzen, 2006: Theories of baroclinic adjustment and eddy equilibration. The Global Circulation of the Atmosphere: Phenomena, Theory, Challenges, T. Schneider and A. Sobel, Eds., Princeton University Press, 22-46. 